\title{
Chemical exchange saturation transfer magnetic resonance imaging and its main and potential applications in pre-clinical and clinical studies
}

\author{
Weiqiang Dou ${ }^{1}$, Chien-Yuan Eddy Lin ${ }^{1}$, Hongyuan Ding ${ }^{2}$, Yong Shen ${ }^{3}$, Carol Dou ${ }^{4}$, Long Qian ${ }^{1}$, \\ Baohong Wen ${ }^{5}$, Bing $\mathrm{Wu}^{1}$ \\ ${ }^{1}$ MR Research, GE Healthcare, Beijing 100076, China; ${ }^{2}$ Department of Radiology, the First Affiliated Hospital of Nanjing Medical University, \\ Nanjing 210029, China; ${ }^{3}$ MR Enhanced Application, GE Healthcare, Beijing 100076, China; ${ }^{4}$ Faculty of Medicine, University of British Columbia, \\ British Columbia, Canada; ${ }^{5}$ Department of MRI, First Affiliated Hospital of Zhengzhou University, Zhengzhou 450052, China
}

Correspondence to: Weiqiang Dou, PhD. MR Research, GE Healthcare, Beijing 10076, China. Email: douweiqiang@gmail.com.

\begin{abstract}
Chemical exchange saturation transfer (CEST) imaging is a novel contrast mechanism, relying on the exchange between mobile protons in amide $(-\mathrm{NH})$, amine $\left(-\mathrm{NH}_{2}\right)$ and hydroxyl $(-\mathrm{OH})$ groups and bulk water. Due to the targeted protons present in endogenous molecules or exogenous compounds applied externally, CEST imaging can respectively, generate endogenous or exogenous contrast. Nowadays, CEST imaging for endogenous contrast has been explored in pre-clinical and clinical studies. Amide CEST, also called amide proton transfer weighted (APT) imaging, generates CEST effect at 3.5 ppm away from the water signal and has been widely investigated. Given the sensitivity to amide proton concentration and $\mathrm{pH}$ level, APT imaging has shown robust performance in the assessment of ischemia, brain tumors, breast and prostate cancer as well as neurodegenerative diseases. With advanced methods proposed, pure APT and Nuclear Overhauser Effect (NOE) mediated CEST effects were separately fitted from original APT signal. Using both effects, early but promising results were obtained for glioma patients in the evaluation of tumor response to therapy and patient survival. Compared to amide CEST, amine CEST is also mobile proton concentration and $\mathrm{pH}$ dependent, but has a faster exchange rate between amine protons and water. The resultant CEST effect is usually introduced at $1.8-3 \mathrm{ppm}$. Glutamate and creatine, as two main metabolites with amine groups for CEST imaging, have been applied to quantitatively assess diseases in the central nervous system and muscle system, respectively. Glycosaminoglycan (Gag) as a representative metabolite with hydroxyl groups has also been measured to evaluate the cartilage of knee or intervertebral discs in CEST MRI. Due to limited frequency difference between hydroxyl protons and water, 7T for better spectral separation is preferred over 3T for GagCEST measurement. The applications of CEST MRI with exogenous contrast agents are still quite limited in clinic. While certain diamagnetic CEST agents, such as dynamic-glucose, have been tried in human for brain tumor or neck cancer assessment, most exogenous agents, i.e., paramagnetic CEST agents, are still tested in the pre-clinical stage, mainly due to potential toxicity. Engineered tissues for tissue regeneration and drug delivery have also shown a great potential in CEST imaging, as many of them, such as hydrogel and polyamide materials, contain mobile protons or can be incorporated with CEST specific chemical compounds. These engineered tissues can thus generate CEST effect in vivo, allowing a possibility to understand the fate of them in vivo longitudinally. Although the CEST MRI with engineered tissues has only been established in early stage, the obtained first evidence is crucial for further optimizing these biomaterials and finally accomplishing the translation into clinical use.
\end{abstract}




\begin{abstract}
Keywords: Chemical exchange saturation transfer (CEST); endogenous contrast; exogenous contrast; tissue engineering
\end{abstract}

Submitted Jun 28, 2019. Accepted for publication Sep 29, 2019.

doi: 10.21037 /qims.2019.10.03

View this article at: http://dx.doi.org/10.21037/qims.2019.10.03

\section{Introduction}

Contrast agents are routinely administered in targeted tissues to enhance image contrast in magnetic resonance imaging (MRI), as these tissues share similar biological properties and thus generate comparable MR values. Gadolinium (Gd) and iron-based contrast agents are the most widely used agents in the clinical setting so far, as they are able to alter tissues' relaxation properties which directly lead to image contrast enhancement with surrounding tissues in MRI. Concerns were, however, raised with the usage of these agents mainly because of potential risks of nephrogenic systemic fibrosis or toxicity. Recent studies reported that the applied Gd related contrast agents may introduce nephrogenic systemic fibrosis despite of its low incidence $(1,2)$. Additionally, oxide particle administration is distributed over different body organs and may cause cytoskeletal disruption, decrease in proliferation and cell death due to generated reactive oxygen species $(3,4)$. Therefore, alternative contrast mechanisms based on natural properties of tissues are urgently needed in in vivo MRI.

\section{Chemical exchange saturation transfer (CEST) MRI}

A novel MR contrast mechanism called "CEST" imaging was first reported by Ward et al. (5), focusing on the proton exchange between targeted chemical compounds and bulk water. Unlike the metallic contrast agents, CEST MRI neither affects the intrinsic MR properties of native tissues, nor causes (potential) risks of toxicity in vivo. In addition, due to its intrinsic characteristics, this technique generates unique image contrast between tissues.

In CEST imaging, as shown in Figure 1, the exchangeable protons in specific molecules are selectively saturated and, after transfer of this saturation by chemical exchange to water protons, detected indirectly through a signal change of bulk water (7). Contrast is thus generated by imaging the signal difference of protons in bulk water and expressed quantitatively using magnetic transfer ratio asymmetry $\left(\mathrm{MTR}_{\text {asym }}\right)$ defined as below:
$\operatorname{MTR}_{\text {asym }}(\Delta w)=\mathrm{S}_{\text {sat }}(-\Delta w) / \mathrm{S}_{0}-\mathrm{S}_{\text {sat }}(\Delta w) / \mathrm{S}_{0}$

in which $\Delta w$ is the frequency difference away from water, and $S_{0}$ and $S_{\text {sat }}$ are the water signal before and after pulse saturation.

As a single transfer of saturation does not generate sufficient contrast effect due to low concentrated solute protons in the saturated chemical compounds, the contrast amplification is achieved by exchange repetition during the saturation, typically resulting in a $\mu \mathrm{M}-\mathrm{mM}$ detection range.

Recently, the mobile protons, commonly used for CEST effects, are those in hydroxyl $(-\mathrm{OH})$, amide $(-\mathrm{NH})$ and amine $\left(-\mathrm{NH}_{2}\right)$ groups, which are present in endogenous molecules or in specifically designed exogenous compounds added to tissues. Therefore, in this work, the main and potential pre-clinical and clinical applications of CEST imaging for endogenous contrast or using exogenous contrast agents were systematically reviewed. The CEST imaging of engineered tissues, as one novel application of exogenous CEST contrast, was also discussed. The clinical potential of these new biomaterials was highlighted.

\section{CEST MRI for endogenous contrast}

Over the past decade, CEST imaging for endogenous contrast has been widely explored in pre-clinical and clinical studies. According to the mobile protons possible for CEST effect mentioned above, CEST imaging is allowed to be categorized as amide CEST, amine CEST and hydroxyl CEST (8).

\section{Applications of Amide CEST}

Amide CEST, also referred to amide proton transfer weighted (APT) imaging, focuses on the exchange between amide protons and bulk water, and thus generates image contrast at 3.5 parts per million (ppm) away from water frequency (9). This exchange rate directly determines the final CEST effect and is considered sensitive to the concentration of applied mobile protons and $\mathrm{pH}$ environment. In lesions, the number of mobile protons 


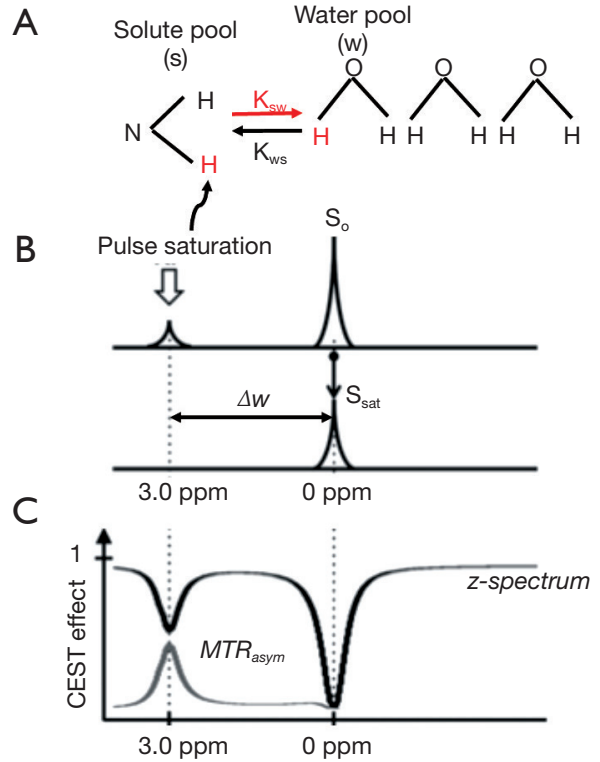

Figure 1 The schematic diagram of chemical exchange saturation transfer: the proton exchange between solute pool and water pool is shown (A); after pulse saturation is applied at frequency of $\Delta w$ away from water peak, the water signal is decreased from $S_{0}$ to $S_{\text {sat }}$ due to the proton exchange between solute and water pool (B); A so called Z-spectrum is measured by normalizing water saturation $\left(\mathrm{S}_{\mathrm{sat}} / \mathrm{S}_{0}\right)$ over a series of saturation frequencies and the CEST effect was expressed quantitatively with $\mathrm{MTR}_{\text {asym }}$ which can be calculated by $\mathrm{S}_{\text {sat }}(-\Delta w) / \mathrm{S}_{0}-\mathrm{S}_{\text {sat }}(\Delta w) / \mathrm{S}_{0}(\mathrm{C})$. Adapted from Vinogradov et al. (6).

in proteins or peptides, as well as the $\mathrm{pH}$ levels, is usually varied at different stages and also shows difference relative to surrounding normal tissues. Based on these pathological features, a number of studies have thus extensively explored the functionalities of APT imaging in clinical diagnosis.

One main application of APT imaging is in ischemia detection. Zhou et al. (9) first reported that the amide protons of proteins and peptides can be measured indirectly with water signal in APT imaging. The acquired APT imaging can be sensitively influenced by changed intracellular $\mathrm{pH}$ environment, as reduced $\mathrm{pH}$ is able to slow the exchange rate between amide protons and bulk water, resulting in a decreased APT effect (9-11). Because of the high sensitivity to $\mathrm{pH}$ differences, this technique has been proposed to detect early ischemia which remains challenging with routine MR examinations such as diffusion weighted imaging or T1/T2 weighted anatomical imaging $(9,10)$. Also, some pre-clinical studies have shown the feasibility of APT imaging in predicting ischemic stroke at acute stage $(12,13)$. This finding is however, not fully consistent with a recent human study focusing on hyperacute stroke patients reported by Tietze et al. (14). Larger clinical studies are therefore required to systematically explore the real potential of APT imaging in this situation.

APT imaging also shows great potential in tumor/cancer assessment (Figure 2). Zhou et al. (11) first investigated the feasibility of APT imaging in the measurement of gliomas at $3 \mathrm{~T}$. The resultant APT signal showed significantly higher value in the solid part than edematous or necrotic area in brain tumors which were confirmed high grade histologically. Moreover, in low grade brain tumors APT imaging however showed comparable effect with the surrounding tissues. Based on these promising findings in lesion assessment, APT imaging has also been extensively applied to measure brain tumors with different grades (15-18), separate malignant tumors from other lesions such as edema (19), radiation necrosis (20), metastases (21), and monitor the tumor progression in malignant gliomas after clinical treatments (22-24). More recently, some pilot studies also investigated APT imaging in glioma patients to identify isocitrate dehydrogenase (IDH) mutation or O6-methylguanineDNA-methyltransferase (MGMT) promotor methylation status (25-27). The obtained APT contrast showed significantly lower levels in IDH-mutant than in IDHwildtype lesions for patients with gliomas as well as high area under the curve (AUC; 92-98\%) in IDH-mutation status prediction $(25,27)$. Also, difference in APT derived parameters was observed between the MGMT methylated and unmethylated glioblastomas (26). Together with these early but promising findings, more rigorous clinical studies are requested in the future. If consistent results are obtained, APT imaging can be suggested as a non-invasive and rapid approach for identifying these genetic markers preoperatively. To date, in routine clinical MR examinations, T2 weighted (T2w), fluid-attenuated-inversion-recovery (FLAIR) imaging and $\mathrm{T} 1$ weighted (T1w) imaging with Gd enhancement are currently playing an important role. $\mathrm{T} 2 \mathrm{w}$ imaging however, can only highlight the combined area of tumor and edema, and enhanced T1w imaging is possible to not only enhance high grade tumors but also low-grade tumors, resulting in erroneous diagnosis. In contrast, since APT imaging may add valuable information on the tumor microenvironment, this technique is suggested to be applied routinely for added information in clinical diagnosis.

Apart from brain tumors, APT imaging may also serve as a possible biomarker in the diagnosis of breast and prostate cancer (28-33). In test-retest measurements, Dula 

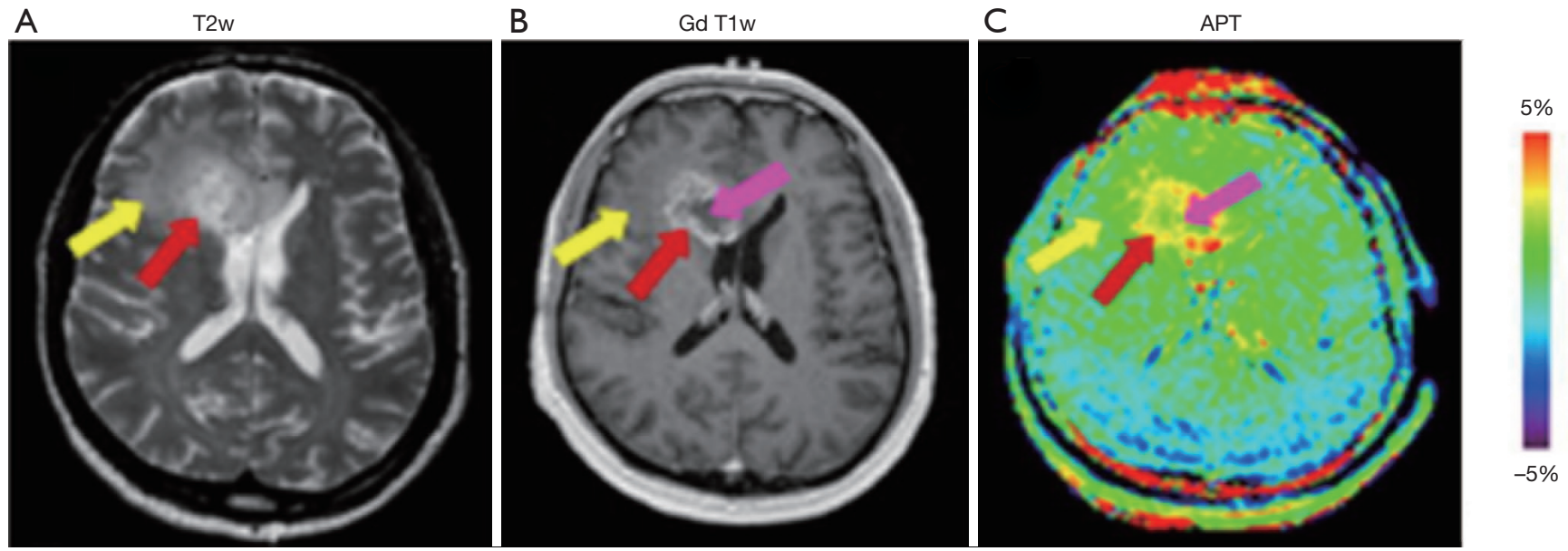

Figure 2 Representative brain images were acquired with multiple MRI techniques. (A) T2-weighted imaging; (B) Gd enhanced T1 weighted imaging and (C) APT imaging for a patient with glioblastoma. While low amide proton transfer weighted (APT) effect was observed in the necrotic region (pink arrow) and peritumoral edematous area (yellow arrow), the tumor rim (red arrow) showed hyperintense APT signal. Adapted from Zhou et al. (15).

et al. $(28,29)$ confirmed the reliability of APT imaging in fibroglandular breast tissue at 3 and $7 \mathrm{~T}$ (3T: mean difference of $\mathrm{APT}_{\text {residual }}$ maps over all subjects $<0.7 \%$; $7 \mathrm{~T}$ : high intra-class correlation coefficient between different measurements of 0.963). Ensured by high reproducibility, this technique was further tested in a small cohort of breast cancer patients before and after neoadjuvant chemotherapy (NAC) $(28,30)$. While preliminary results showed the feasibility of APT signal in the assessment of NAC response, further longitudinal studies with large sample size are however required for more systematical investigation.

APT imaging also has applications in the detection of neurodegenerative diseases, e.g., Alzheimer's disease (AD) (34), Parkinson's disease (PD) (35-37) and multiple sclerosis (MS) (38). Preliminary results have shown that when compared with controls, AD patients had increased APT signal in the bilateral hippocampus region which correlated directly to clinical disease severity (34). In PD patients, lower APT signal was found in the substantia nigra and red nucleus relative to healthy controls. Furthermore, the strength of signal was consistently decreased with disease severity from early to advanced stage.

An originally obtained APT effect includes not only the pure APT signal at $3.5 \mathrm{ppm}$ but also the exchange-relayed Nuclear Overhauser Effect (rNOE) of aliphatic protons in mobile macromolecules at upfield side of water spectrum $(-3.5 \mathrm{ppm})$, the conventional magnetization transfer (MT) effect from the semi-solid components at both downfield and upfield sides of water peak $( \pm 3.5 \mathrm{ppm})$ as well as the symmetric direct saturation (DS) effect (39). This composite CEST effect can be influenced by the B0 field and the applied parameters for B1 saturation (40). With low B1 power used (e.g., $0.6 \mu \mathrm{T}$ ), the integral of all upfield saturation effects ( $\mathrm{rNOE}+\mathrm{MT}+\mathrm{DS})$ at $-3.5 \mathrm{ppm}$ is larger than the summed effect (APT + MT + DS) at the opposite side in normal brain tissues, while comparable effects in both sides are obtained in tumor largely due to the replaced white matter with myelin lipid by increased tumor cells $(39,40)$. In contrast, an opposite pattern is obtained, if the applied B1 power is higher (e.g., $2.1 \mu \mathrm{T}$ ).

As the CEST effect has multiple contributions, the $\mathrm{MTR}_{\text {asym }}$ analysis $\{\mathrm{Eq} .[1]\}$ conventionally applied to quantify CEST data is not able to interpret each single component included. To better understand the NOE or pure APT signal, multiple approaches have been proposed. A mathematical method called extrapolated semisolid magnetization transfer reference (EMR) has been reported for pure APT $\left(\mathrm{APT}^{\#}\right)$ and $\mathrm{NOE}\left(\mathrm{NOE}^{\#}\right)$ signal fitting $(41,42)$. This method estimates a reference $Z$-spectrum $\left(Z_{\mathrm{EMR}}\right)$ of only DS and MT effects by using the $\mathrm{Z}$-spectrum intensities acquired at large frequency offsets where no CEST effect is expected. The resultant pure NOE and APT signal can be calculated by the following equations:

$$
\begin{aligned}
& \mathrm{NOE}^{\#}=Z_{\text {EMR }}(-3.5 \mathrm{ppm})-\mathrm{Z}(-3.5 \mathrm{ppm}) \\
& \mathrm{APT}^{\#}=Z_{\mathrm{EMR}}(3.5 \mathrm{ppm})-\mathrm{Z}(3.5 \mathrm{ppm})
\end{aligned}
$$


Using this method, more specific APT effect has been reported in acute stroke and brain tumor studies (41-43), although $\mathrm{NOE}^{\#}$ signal was still somewhat contaminated by MT effect (39).

APT and rNOE signals can also be fitted pixelwisely using multiple Lorentzian functions (44). The corresponding label $\left(Z_{\text {lab }}\right)$ as well as a reference $Z$-spectrum $\left(Z_{\text {ref }}\right)$ can be obtained for separate APT and rNOE effects. The non-relaxation-compensated magnetization transfer Lorentzian difference $\left(\mathrm{MTR}_{\mathrm{LD}}\right)$ of APT or rNOE can be in general expressed as (45):

$$
\mathrm{MTR}_{\mathrm{LD}}=\mathrm{Z}_{\mathrm{ref}}-\mathrm{Z}_{\mathrm{lab}}
$$

where $\mathrm{MTR}_{\mathrm{LD}}$ for the amide peak at $3.5 \mathrm{ppm}$ is $\mathrm{APT}_{\mathrm{LD}}$ and for the rNOE signal at $-3.5 \mathrm{ppm}$ is $\mathrm{NOE}_{\mathrm{LD}}$. To additionally compensate for the relaxation time, a method called apparent exchange-dependent relaxation (AREX) has been used $(44,46)$ :

$$
\operatorname{AREX}=\left(1 / Z_{\text {lab }}-1 / Z_{\text {ref }}\right) / T 1
$$

With this equation, the relaxation compensated APT contrast $\left(\mathrm{APT}_{\mathrm{AREX}}\right)$ and $\mathrm{NOE}$ contrast $\left(\mathrm{NOE}_{\mathrm{AREX}}\right)$ can be obtained. To further calculate pure APT signal by removing the contributions of downfield rNOE, the downfield-rNOEsuppressed APT signal (dns-APT) can be given by (47):

$$
\operatorname{dns}-\operatorname{APT}(+\Delta \omega)=\operatorname{AREX}(+\Delta \omega)-r_{\mathrm{rNOE}} \times \operatorname{AREX}(-\Delta \omega) \quad[6]
$$

where $\Delta \omega=3.5 \mathrm{ppm}$ and $r_{\mathrm{rNOE}}=0.2$.

Imperfect B0 and B1 fields, due to the limitations of hardware, can also introduce negative effects on CEST quantification (8). Inhomogeneous B0 field can cause the acquired Z-spectrum with chemical shifts, resulting in an erroneous assessment of CEST effect, while imperfect B1 power can lead to an insufficient saturation of the exchanging pool. To overcome these artefacts, several $\mathrm{B} 0$ and $\mathrm{B} 1$ correction methods have been proposed (48-50). One widely used B0 correction method is to acquire an independent $\mathrm{B} 0$ reference map prior to CEST measurement. The shifted $\mathrm{Z}$-spectrum due to imperfect $B 0$ field can thus be recovered accordingly (48). Water saturation shift reference (WASSR) is another $\mathrm{B} 0$ correction method often applied (49). With a weak and short B1 power, a $\mathrm{Z}$-spectrum dominated by direct saturation is generated and provides sub-Hertz accuracy for spectral frequency alignment. In addition, a combined B1/B0 correction method called water shift and B1 (WASABI) was recently proposed (50). Simultaneous B0 and B1 mapping can be rapidly acquired by using an off-resonant rectangular preparation pulse and applied for B0 and B1 correction in CEST experiment.

Using advanced methods discussed above, the NOE mediated CEST effect as well as the pure APT signal have been well separated. These CEST metrics have been further applied recently in the evaluation of brain tumor response to therapy at $3 \mathrm{~T}$ and $7 \mathrm{~T}$ (51-53). With multiple CEST metrics (i.e., $\mathrm{MTR}_{\mathrm{NOE}}$ and $\mathrm{MTR}_{\text {Amide }}$ ), progressors showed significantly different changes in glioblastoma than non-progressors before and 2 weeks after chemo-radiation therapy (51). Moreover, higher CEST effects, including

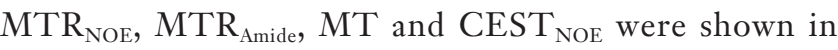
patients with progressed than non-progressed tumors before treatment. Similar studies were also performed by Regnery et al. (52) and Meissner et al. (53). Using AREX method, the isolated CEST contrasts (NOE mediated CEST signal and dns-APT) showed significantly different signal intensities for glioma patients before and after treatment, and the feasibility in discriminating progressive from stable tumors $(52,53)$. With these promising results, CEST derived metrics have shown the possibility to characterize tumor aggressiveness and act as imaging biomarkers of glioma response at early time of the treatment. In addition, CEST derived contrasts were also used to investigate the association with survival in high grade glioma patients (54). Significant correlation was revealed between the CEST metrics applied and patient overall survival as well as progression-free survival.

\section{Applications of Amine CEST}

Mobile protons from endogenous mobile proteins, peptides or amino acids, are also able to exchange with bulk water, resulting in a CEST effect at $1.8-3 \mathrm{ppm}$ downfield from water signal (55). Compared with amide protons, the mobile protons in amine group show a faster exchange rate with bulk water. This exchange rate is also concentration and $\mathrm{pH}$ dependent, and can be too fast for CEST effect generation at $\mathrm{pH}$ level higher than 7.0. Therefore, notable amine CEST effect is more likely to be observed in acidic microenvironments. Glutamate $(\mathrm{Glu})$ and creatine $(\mathrm{Cr})$ are the two main metabolites with amine groups for CEST imaging, and thus are called GluCEST $(56,57)$ and CrCEST (58), respectively.

Glutamate is a major excitatory neurotransmitter in the central nervous system. The concentration level of this metabolite is directly linked with multiple neurological and psychiatric diseases (59). GluCEST imaging has been 


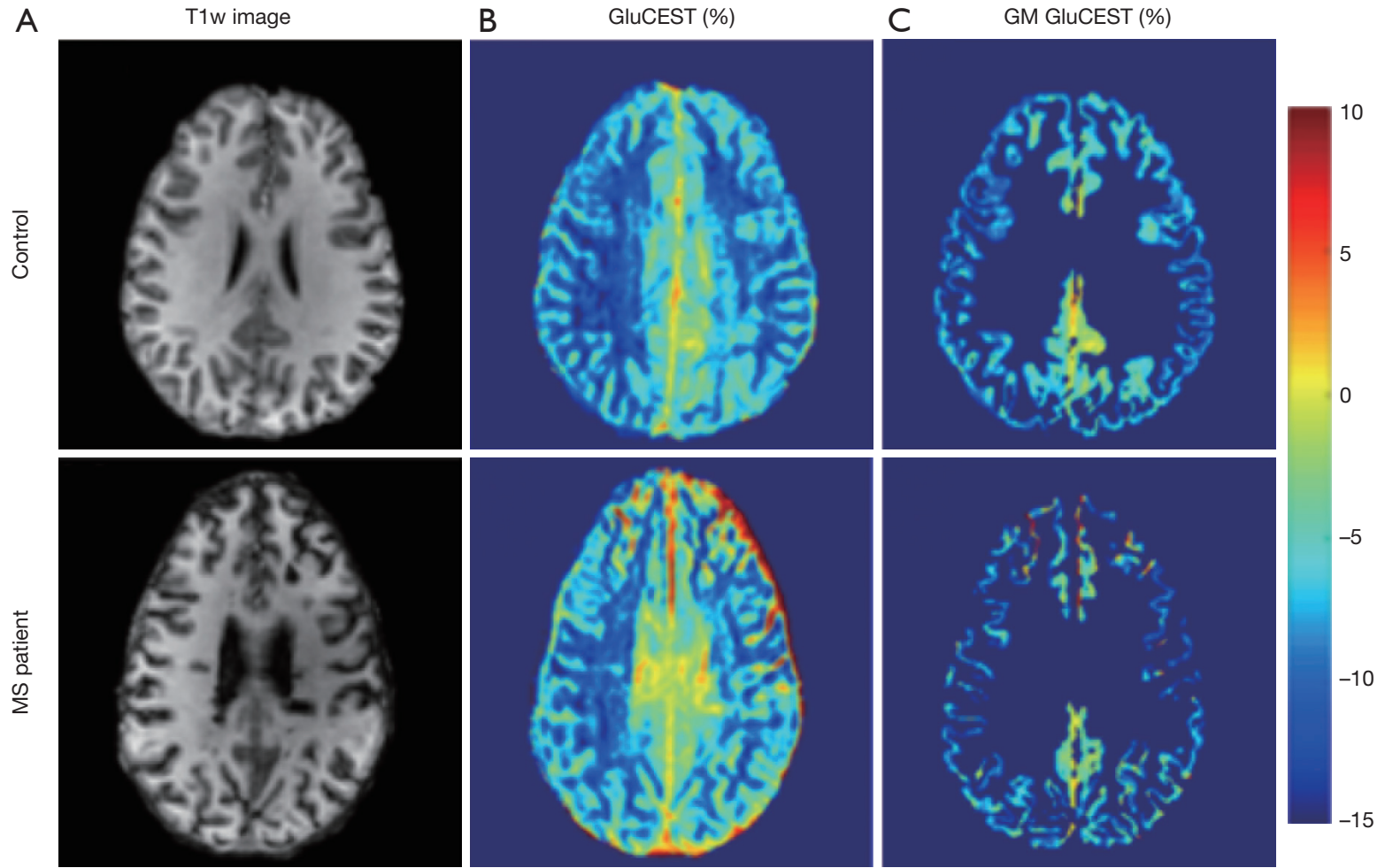

Figure 3 Representative T1 weighted anatomical brain images (A) and the separate glutamate chemical exchange saturation transfer (GluCEST) contrast maps of brain tissues (B) and of gray matter tissues (C) were obtained for a healthy control and a patient with multiple sclerosis (MS). A significant increase of GluCEST contrast was found in cortical gray matter especially at its prefrontal region in the MS patient than in the healthy control. Adapted from O'Grady et al. (61).

applied in an animal AD model to evaluate the abnormal Glu concentrations in the brain (60). Confirmed by ${ }^{1} \mathrm{H}$ MRS measurement, significantly reduced Glu level $(\sim 30 \%)$ was revealed in whole brain. For MS patients with cognitive impairment (CI), glutamate concentration was also quantified with GluCEST imaging, showing notable increase in the cortical gray matter (GM) and especially at its prefrontal region than that of healthy control (61) (Figure 3). Together with the strong correlation with clinical CI test, GluCEST MRI may become a useful tool for GM pathology and CI evaluation. Young people with clinical high risk for psychosis showed similar symptoms relative to schizophrenia patients. Using GluCEST imaging, lower Glu concentration level across cortex and sub-cortex regions was observed in both groups than that of controls. GluCEST may thus be helpful in early detection of patients at risk for future psychosis (62). While normal MR brain images are obtained in one-third epilepsy patients and thus introduce challenges in clinical diagnosis, GluCEST imaging showed the feasibility in detection of non-lesional temporal lobe epilepsy qualitatively and quantitatively with enhanced contrast (63). In addition to neurological disorders, GluCEST has also been tested for the feasibility of brain tumor detection (64) and Glu quantification in spinal cord (65). While promising results were obtained, well designed clinical studies with large groups of patients are required further.

Creatine (Cr) is an important biomarker of energy metabolism in the muscle system (66). Through creatine kinase reaction (CK), $\mathrm{Cr}$ can be rapidly reversibly converted to phosphocreatine (PCr) during exercise. Adenosine triphosphate (ATP) is then generated with the consumption of $\mathrm{PCr}$ and provides required energy for muscle contraction (58).

$$
C r+A T P \leftrightarrow A D P+P C r+H^{+}
$$

Based on this dynamic change in both metabolite concentrations, a variety of 3 and 7T studies have investigated the potential of CrCEST imaging in monitoring the concentration variations of both metabolites in calf muscles of healthy humans before and after exercise $(58,67,68)$. The 

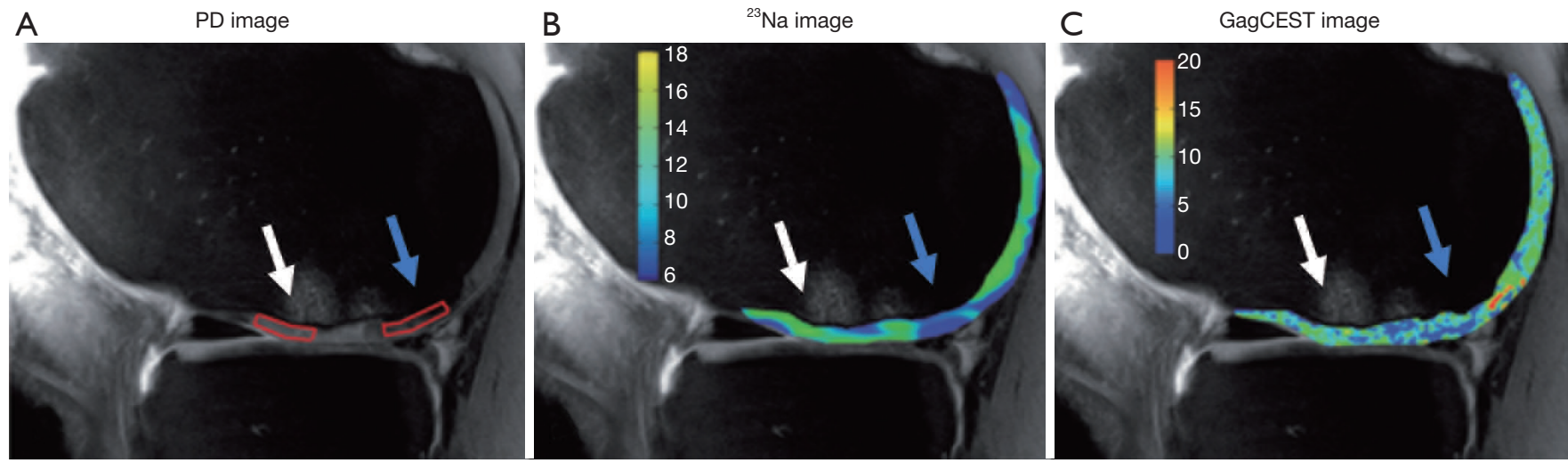

Figure 4 Cartilage quality assessment using glycosaminoglycan chemical exchange saturation transfer (GagCEST) MRI. A representative proton density (PD) weighted anatomical image was acquired for a patient with cartilage tissues repaired (A). The regions of interest (ROI) $\mathrm{s}$ were selected in the native (left) and repaired (right) cartilage tissues, respectively. The corresponding ${ }^{23} \mathrm{Na}$ image (B) and the GagCEST map of cartilage (C) were also acquired. White and blue arrows were used to respectively denote the ROIs of the native (left) and repaired (right) cartilage tissues in the PD (A), ${ }^{23} \mathrm{Na}(\mathrm{B})$ and GagCEST maps (C). Different CEST effects were found between native and repaired tissues. Adapted from Schmitt et al. (75).

feasibility of CrCEST imaging was confirmed by the gold standard of 31P MRS. These first but solid evidences might suggest further clinical applications of CrCEST imaging in muscular diseases. CrCEST imaging was also extended to evaluate the myocardial viability, as cardiac dysfunction has been closely linked with the abnormal levels of metabolite concentrations in the CK system (69). Although promising results in animal studies and one patient with myocardial infarction were obtained, further work is necessary to evaluate the real clinical potential of CrCEST in cardiac diseases.

\section{Applications of Hydroxyl CEST}

The mobile protons in the hydroxyl group are also able to exchange with bulk water (7). The resultant CEST effect is thus generated and resides at about $1.0 \mathrm{ppm}$ next to the water signal. Glycosaminoglycan (Gag) and glycogen are the two main metabolites with hydroxyl groups and have been investigated for CEST properties in (pre-)clinical studies (70-73). Due to the small frequency difference between hydroxyl protons and water at 3T, 7T for better spectral dispersion and higher signal-to-noise ratio, is also preferred to be used for CEST measurement (70-72).

Gag serves as an important biomarker to evaluate the cartilage of knee or intervertebral discs. Low Gag concentration level is considered an effective indicator for early knee osteoarthritis and intervertebral disc degeneration. While Gag concentration can be measured with quantitative T1rho values or sodium $\left({ }^{23} \mathrm{Na}\right)$ imaging, GagCEST imaging showed promise in accurate Gag quantification. With GagCEST imaging, the Gag concentration was measured in the knee cartilage of patients with knee pain, and showed a significant negative correlation with pain scores and cartilage grades confirmed (74). This technique has also been applied to measure Gag concentration for the patients after cartilage repair surgery (Figure 4) or with cartilage disorders. Comparable Gag assessment was obtained relative to ${ }^{23} \mathrm{Na}$ MRI, delayed Gd-enhanced MRI or T2 mapping of cartilage, respectively $(75,76)$. In addition to cartilage disorders, GagCEST imaging has also been demonstrated in the detection of lumbar or cervical intervertebral disc degeneration $(77,78)$. The Gag content measured by GagCEST effect was found decreased in the degenerated lumbar discs of patients with spondyloarthritis than healthy controls (79). Furthermore, a significant inverse correlation was separately observed between the Gag content and the Pfirrmann scores classifying the lumbar disc alteration in morphology (80), and between the Gag content and the degree of low back pain (81). However, Gag content in intervertebral discs was also found not to be comparable in healthy controls but with different genders or body mass index (82). Further studies are therefore necessary to be performed for systematic investigation of the specificity of GagCEST imaging in large clinical population.

Glycogen, the major storage form of glucose in mammalian tissues, plays an essential role in systemic 
glucose homeostasis $(7,73)$. Abnormal level of this metabolite was reported to closely link with different physiological disorders including inherited disorders, obesity and type 2 diabetes. Accurate quantification of this metabolite is thus crucial (73). While ${ }^{13} \mathrm{C}$ MRS is conventionally applied as a quantitative method to estimate glycogen concentration, CEST imaging has also shown the possibility to detect the hydroxyl protons in glycogen at $0.5-1.5 \mathrm{ppm}$ for quantitative assessment. Due to high abundance of glycogen in liver and muscle, glycoCEST has been applied to monitor the breakdown of glycogen during liver perfusion in animal (73), and showed noticeable CEST effect in human calf muscle (6), respectively.

\section{CEST MRI for exogenous contrast}

In addition to presenting in tissues as endogenous agents, chemical compounds with exchangeable protons, i.e., $-\mathrm{NH},-\mathrm{NH}_{2}$ and $-\mathrm{OH}$, can also be intravenously given to generate exogenous CEST effect (6). Exogenous, compared to endogenous agents, can control the CEST contrast by customizing the total amount of mobile protons administered, so that the introduced dosage can be minimized without sacrificing CEST effect (83).

While most diamagnetic CEST (diaCEST) applications focus on endogenous mobile protons as mentioned in the previous section, several diaCEST agents have also been administered externally for exogenous contrast in vivo. One typical example is glucose. As the primary energy source in most tissues, glucose requires accurate quantification in vivo, as impaired glucose uptake was reported to closely associate with various pathological situations (84). However, because of limited spectral dispersion between hydroxyl and water peaks and low quantity at physiological level, it is usually problematic to quantitatively estimate glucose-derived CEST effect at clinical field strength (8). Alternatively, an extra biodegradable CEST agent dynamic-glucose (D-glucose) has been administered into pathological lesions and measured dynamically with CEST imaging for exogenous contrast (85-88). A similar detection of dynamic glucose alteration in brain or neck cancer tissues was observed in glucose enhanced images (Figure 5) when compared with $18 \mathrm{~F}$-fluorodeoxyglucose $\left({ }^{18} \mathrm{~F}\right.$ FDG $)$ measurement or Gdenhanced MRI widely applied clinically $(84,87,88)$. In the meanwhile, chemical exchange-sensitive spin-lock (CESL) imaging, as a technique for T1rho weighted glucose enhanced imaging (glucoCESL), has also been applied to investigate the dynamic changes of injected D-glucose in animal and human brain tumors (89-91). By monitoring the glucoCESL maps changed dynamically, Jin et al. (89) found that the initial increased CESL contrast in tumor region, qualitatively similar to Gd-enhancement imaging, was due to the extracellular glucose accumulation, whereas the CESL contrast at the later period might be contributed by glucose uptake in the intracellular compartment. After further investigating this in glioblastoma patients at $7 \mathrm{~T}$ $(90,91)$, the images showed distinct contrast in tumor regions relative to healthy tissues, indicating a feasibility to identify a pathophysiologically increased glucose uptake in tumor area. Also, the temporal resolution is seven seconds. Therefore, the dynamic contrast of glucoCESL can be suggested as an indicator for glucose uptake in tumors.

In addition, some $\mathrm{X}$-Ray/CT contrast agents such as iopamidol and iopromide, often structured with amide exchangeable protons around aromatic ring (also known as aryl amide), have shown feasibilities to generate CEST effect at unique frequencies (e.g., in the range of 4-6 ppm) which do not overlap with the frequencies of endogenous amide $(92,93)$. Due to high $\mathrm{pH}$ dependent CEST effect, these agents, also called acidoCEST, have been applied for tumor acidosis assessment and $\mathrm{pH}$ measurement in (pre-)clinical CEST imaging studies (94-96). Besides that, diaCEST liposomes have also been developed as a biodegradable agent in CEST imaging to follow the dynamic changes of liposomes in vivo $(97,98)$. As reported by Liu et al. (97), liposomes were incorporated with different mobile proton groups from glycogen $(-\mathrm{OH})$, polyL-lysine (-NH2) and L-arginine (-NH). Multiple CEST contrasts were thus displayed distinctively at respective chemical shifts, allowing the observation of dynamic liposome uptake in lymph in vivo.

The majority of exogenous agents reported so far, belongs to paramagnetic CEST (paraCEST). ParaCEST agents contain in most cases metallic ions (e.g., lanthanides) incorporated with molecules with exchangeable protons (6). With paraCEST agents, strong CEST effects are usually obtained at tremendously larger chemical shifts away from water frequency than those at diaCEST agents (i.e., $<6 \mathrm{ppm}$ ) (8). Clean excitation of resonances is thus easy to achieve without much water signal saturation (7). In addition, paraCEST agents have much faster exchange rates than diaCEST agents, which allow for more sensitive CEST effect generated, although high saturation power is usually implemented to increase saturation efficiency (7). To date, a variety of paraCEST agents have been developed and many of them have already been investigated in 


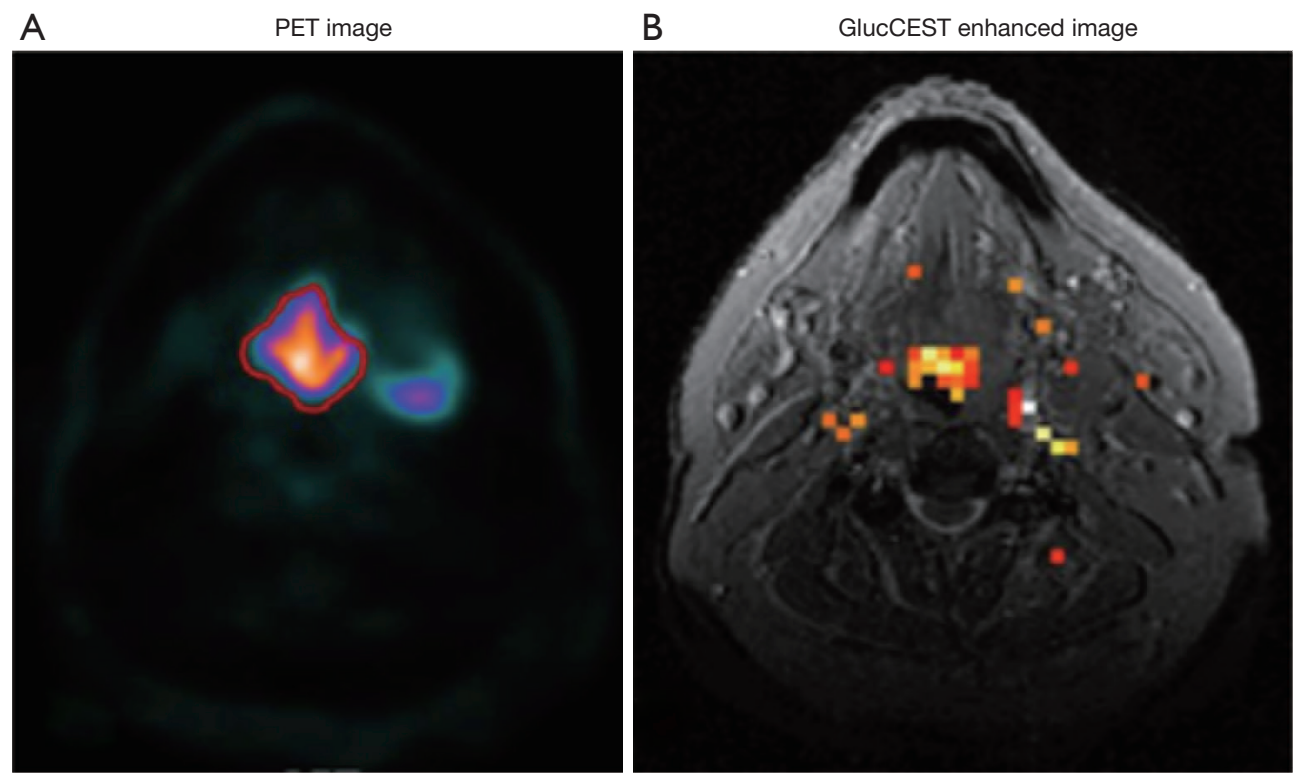

Figure 5 For a representative tumor patient, the tumor lesions have been revealed by two hyperintense regions at an ${ }^{18} \mathrm{~F}$-fluorodeoxyglucose positron emission tomography (PET) image slice (A); the corresponding glucose enhancement (GCE) image at the same slice as the PET image was also shown (B). The hyperintense GCE signals, indicating the tumor tissues, were compared with the PET image qualitatively. A general (but not perfect) correlation between both images was observed. Adapted from Wang et al. (87).

in vivo environment (99-103). For example, Delli Castelli et al. (104) developed a multi-contrast exogenous MRI agent by loading liposomes with paramagnetic complexes, Gd-HPDO3A complex as well as [Tm-DOTMA $]^{-}[\mathrm{Na}]^{+}$. Injecting this agent into a mouse tumor model, the correspondingly generated CEST, T1 and T2 contrasts were able to monitor the in vivo fate of liposomes and their payload in a kinetic model. Another paramagnetic agent DOTAM-glycine-lysine was also administered into an animal glioblastoma tumor model (105). The dynamic changes of the generated on-resonance paramagnetic chemical exchange effect (OPARACHEE) was used to understand the agent uptake and retaining in in vivo environment. Moreover, after injecting a similar agent into mouse kidney, the corresponding OPARACHEE also showed the feasibility to monitor the accumulation and clearance of agent dynamically (106). Additionally, to investigate liver perfusion in vivo, Europium(III)-1,4,7,10tetraazacyclododecane-1,7-di- $N$-methylacetamide-4-10di-N(m-phenylborate)acetamide (Eu-D2MA-2PB) as a paramagnetic compound was combined with an exogenous glucose agent. A 17\% higher CEST contrast was observed in mouse liver when comparing dynamic perfusion with and without glucose at $42 \mathrm{ppm}$ (107). Although promising results have been obtained in vivo, the application of
paraCEST agents is still limited to be translated into clinic, mainly because of the potential toxicity from metallic ions included (55). However, with the rapid progress of chemical technology, this concern might not be crucial in the near future as higher stability and thermodynamic level are assumed to be achieved in the newly designed agents (7). Therefore, the paraCEST approach is considered having a great potential in future clinical applications.

Apart from those agents discussed above, engineered tissues, designed to act as biological substitutes in regenerative medicine, are naturally biocompatible and biodegradable in vivo, and thus favourable in in vivo applications $(108,109)$. More importantly, CEST specific chemical compounds are usually observed in a variety of engineered tissues (110-115). Because of these, the newly designed biomaterials nowadays have been gradually realized being capable of serving as good candidates of CEST agents (116-118). Therefore, in the last part of this review, we would like to discuss the current status of engineered tissues in CEST imaging and highlight their clinical potential.

\section{CEST MRI in tissue engineering}

Tissue engineering is a newly emerging biomedical 
technology, aiming to develop biological substitutes to restore, replace or regenerate defective tissues and their functions $(108,109)$. In contrast to surgical tissue transplantation and replacement with biomechanical devices, engineered tissues do not rely on donor availability or device replacement after wearing out (109). Moreover, due to the biocompatibility and biodegradability in nature, these biomaterials also have the potential to serve as carriers with drugs loaded into target cells at modulated release rates in gene therapy applications $(111,112,114,115)$. As engineered tissues show such a great potential of becoming a valuable alternative in biomedical field, the fate of these materials in vivo requires to be first well understood after surgical implantation.

It is however, usually problematic to investigate these biological features in vivo, because the engineered and parent natural tissues often have similar biological properties and thus similar MR parameter values, resulting in poor image contrast (109). To enhance the image contrast between engineered and surrounding tissues, contrast agents such as Gd based or iron related materials, are usually selected in MR imaging (119), although potential clinical risks of these applications were discussed (1-4).

Different from these conventional MR contrast agents, CEST, as a non-metal image contrast mechanism, doesn't change the intrinsic properties of the targeted tissues and thus introduce negative effects such as toxicity, but enhances the MR image contrast through exchanging mobile protons between functionalized molecules and water pool (7). Recently, exploiting the CEST MRI properties of engineered tissues becomes a novel application, as many of them contain mobile protons potentially for CEST effects or multiple of these protons can be added into the tissue compounds for enhanced sensitivity (116-118). The resultant image contrast generated may thus turn out to be essential to monitor these tissues in vivo longitudinally or further control them in tissue regeneration or drug delivery.

According to some pilot CEST MRI studies, several types of gell-like biomaterials, have been systematically investigated in the aspects of CEST properties in vitro and in vivo (116-118). Through monitoring the CEST contrast altered dynamically, the biological features of these biomaterials were assessed longitudinally after implantation into animal models. So far, the studies to explore the CEST properties in engineered tissues are still at early stage. Some engineered tissues already studied can be categorized as hyaluronic acid (HA) hydrogel and polyamide gelly materials.

\section{Hyaluronic acid hydrogel}

Hyaluronic acid is a major component of extracellular matrices with high biocompatibility and biodegradability (110). The resultant HA hydrogel after solving into water becomes injectable and can be used for drug delivery and tissue regeneration $(111,112)$. Due to the mobile protons included, some similar studies have tested the CEST properties of HA hydrogel acting as a potential exogenous contrast agent in CEST MRI (116-118). Liang et al. (117) systematically investigated the CEST properties of HA hydrogel with and without gelatine incorporated. Compared to commercially available HA, the material with gelatine showed stronger CEST effect at $3.6 \mathrm{ppm}$ because of the amide protons present in gelatine. After injecting into mouse brain model, the biodegradability of this gelly biomaterial was evaluated longitudinally and showed an agreement with the histological analysis.

Furthermore, native HA can be functionalized with different chemo-selective groups to form chemically crosslinked hydrogels for biomedical applications (110). Two functionalized HA derivatives containing functional groups of aldehyde (HA-aldehyde) or hydrazide (HA-hydrazide), mixed in a solution at equal and low concentration (e.g., $2 \%$ ), become a gel at room temperature within 30 seconds. To monitor its dynamic interaction with native tissues in vivo, the CEST MRI of this hydrogel was systematically investigated for the first time in vitro at different experimental conditions (120). As a result, an optimal CEST effect from -OH group of this new functionalized hydrogel was obtained at $1.0 \mathrm{ppm}$ by using the saturation amplitude of $150 \mathrm{~Hz}$ and duration of $3,000 \mathrm{~ms}$ at room temperature (Figure 6).

\section{Polyamide gelly material}

Poly(amido amine)s (PAA) polymers, as an important class of cationic polymers, are chemical compounds with good water solubility and biodegradability $(113,114)$. They have been proposed for a number of biomedical applications such as drug/gene delivery and as a nanogel for imaging $(114,115)$. Three different functionalized PAA polymers with tuneable bioreductive degradability have been newly developed to control the spatiotemporal release of genes, of which the degradation behaviour is controlled by incorporating different steric hindrance around the disulfide bond (114).

A newly developed PAA material poly(N, N'-methylene 
A

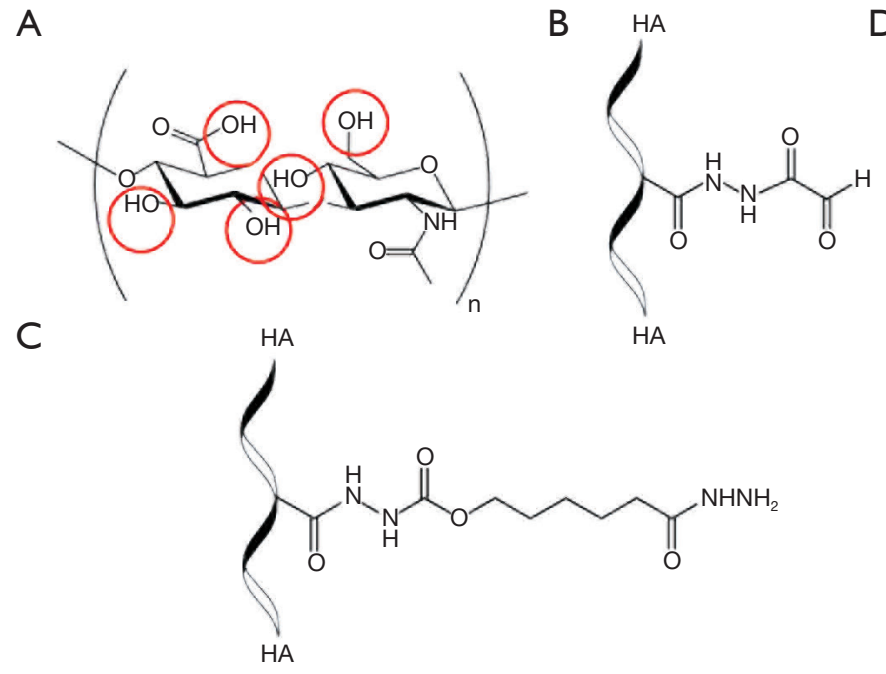

B

D

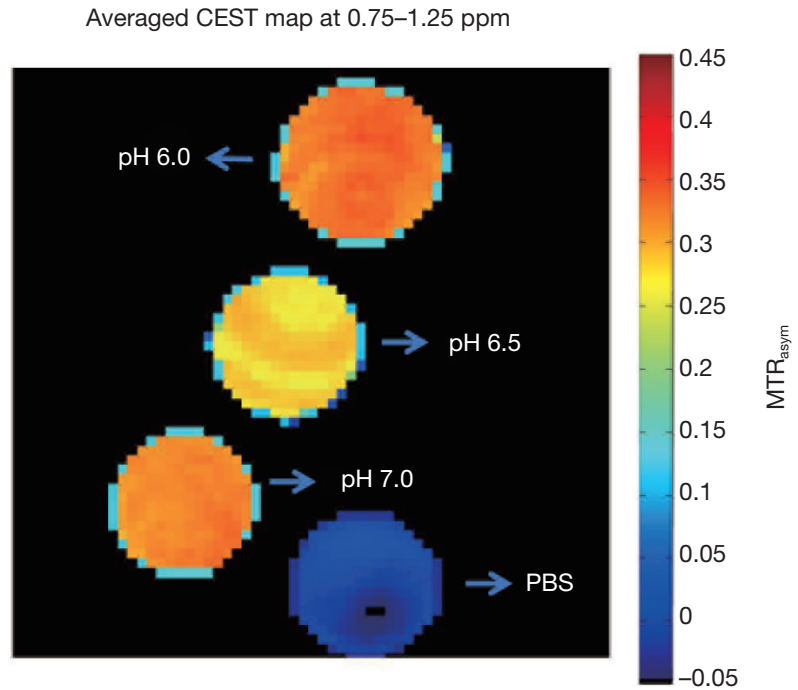

Figure 6 In vitro chemical exchange saturation transfer (CEST) MRI of hyaluronic acid hydrogel. Chemical structures of native hyaluronic acid (HA, A); aldehyde modified HA (B) and hydrazide modified HA (C). Exchangeable hydroxyl (red circles) protons for CEST imaging are indicated. With optimized experimental conditions, the corresponding averaged CEST image of the hydrogels at different $\mathrm{pH}$ levels and a PBS sample between 0.75 and $1.25 \mathrm{ppm}$ was shown (D). Adapted from Dou et al. (120).

bisacrylamide 4-aminobutanol) (MBA-ABOL), consisting of exchangeable protons in amide and hydroxyl groups, has been investigated for CEST properties in a recent study (121). After vortexing with milliQ water at room temperature, MBA-ABOL powders at the concentration level of $1 \%$ became a gel-like material in about 2 minutes. After optimizing the CEST effect through in vitro experiments, this material was embedded into a collagen scaffold and injected into a rat leg for further ex vivo investigation. Notable MTR $_{\text {asym }}$ representing CEST signal was observed at about $1.5 \mathrm{ppm}(20 \%)$ and $4 \mathrm{ppm}(50 \%)$ (Figure 7).

As tissue engineering field is now being rapidly developed, a wild variety of engineered tissues in addition to those mentioned above may also become potential candidates for CEST MRI contrast. For example, polyisocyanopeptide (PIC) hydrogel is a synthetic gel that gelates at low concentrations and mimics in nearly all aspects gels prepared from intermediate filaments (122). Therefore, PIC hydrogel has a great potential to replace other gels as an engineered tissue. PIC is a liquid at temperatures below $4{ }^{\circ} \mathrm{C}$ and fully converts to a gel above $16^{\circ} \mathrm{C}$. This interesting property allows PIC to be injected as a liquid into a targeted tissue and to become gelated in vivo at body temperature. Due to the exchangeable amide protons in the gel, a strong CEST effect can be potentially expected. It thus requires a validation study in the near future.

To summarize, although CEST MRI of engineered tissues has only been established in pre-clinical stage so far, the first in vivo evidence is essential to be acquired to support the development and optimization of engineered tissues. With the qualitative and quantitative knowledge obtained, it has been demonstrated that engineered tissues own the potential of functioning as safe exogenous CEST contrast agents while implanted in vivo for biomedical purposes. Clinical researchers are thus allowed to understand their fate in vivo and make necessary steps before translating them into clinical use. In the future, patients implanted with engineered tissues will thus greatly benefit from this technique.

\section{Challenges of CEST MRI in clinical implementation}

For CEST MRI, encouraging results have been shown and mostly validated in animal models or pilot human studies. To fulfill a further translation into clinic, in addition to the potential toxicity of CEST agents (mostly paraCEST agents) and B0/B1 inhomogeneities discussed above, several other issues are also requested to be addressed beforehand, including the requirements for low power deposition, limited scan time as well as the CEST signal interpretation.

The amount of power deposition is always a crucial point 
A

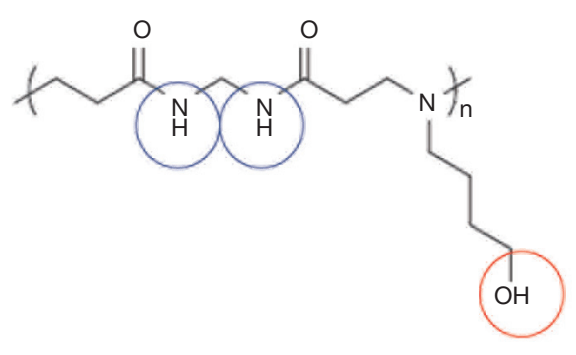

B

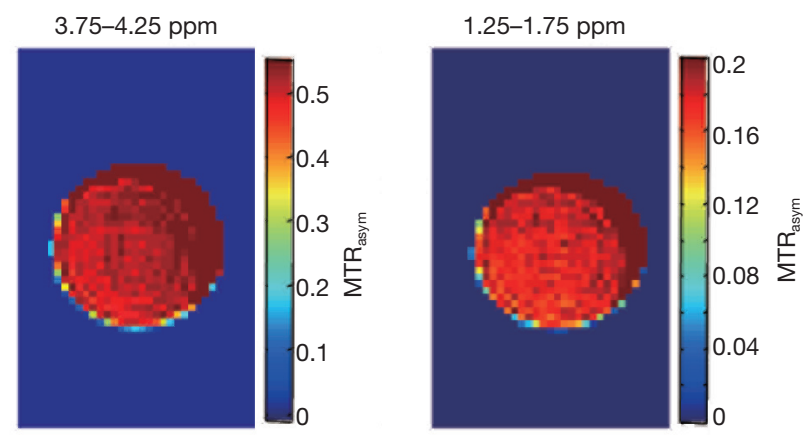

C

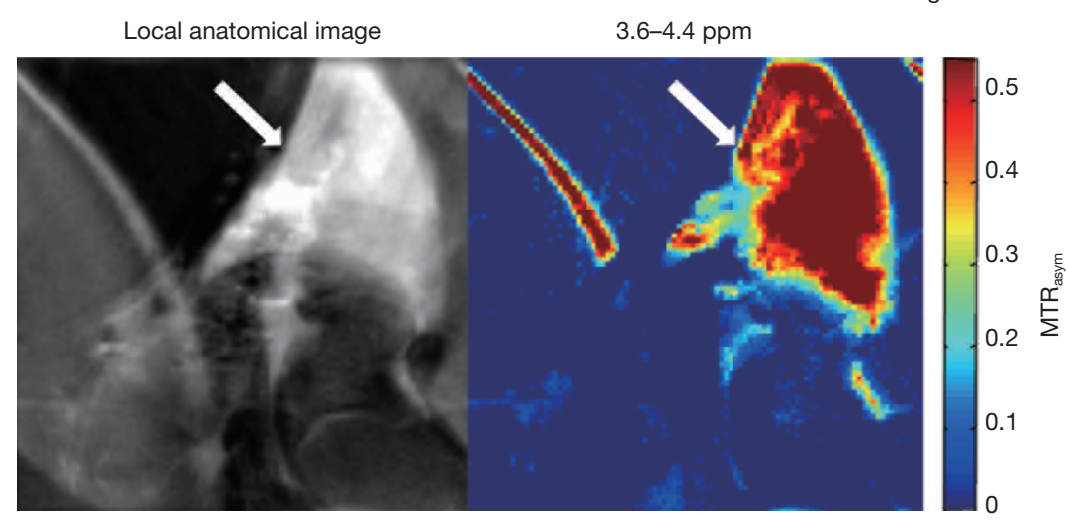

Averaged CEST MR image

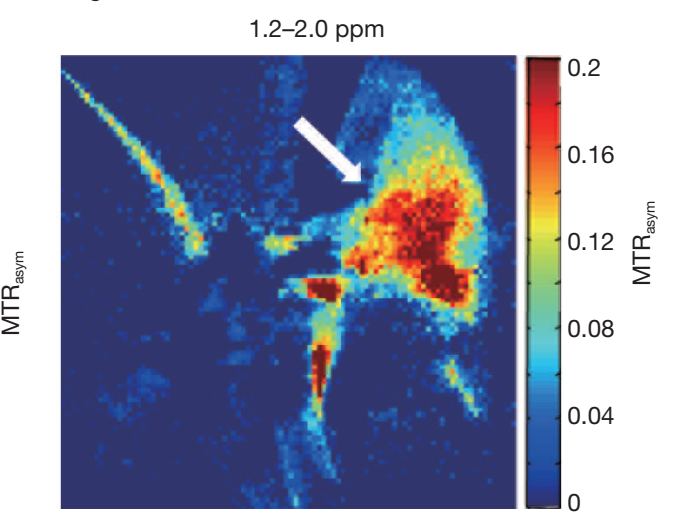

Figure 7 In vitro \& ex vivo chemical exchange saturation transfer (CEST) MRI of poly(N, N'-methylene bisacrylamide 4-aminobutanol) (MBA-ABOL) hydrogel. (A) Chemical structure of MBA-ABOL showing exchangeable amide (blue circle) and hydroxyl (red circle) protons suitable for CEST imaging; (B) using the optimized scan parameters, the averaged CEST images of the MBA-ABOL sample in vitro from 3.75 to $4.25 \mathrm{ppm}$ and from 1.25 to $1.75 \mathrm{ppm}$ were shown; (C) local anatomical image of the right posterior leg of a rat model revealing the location of the implanted MBA-ABOL solution embedded into a scaffold (indicated with a white arrow) was shown. The corresponding CEST MR images of the material were also derived from averaging a significant MTR $_{\text {asym }}(\sim 50 \%$, white arrow) between 3.6 and 4.4 ppm and from averaging a strong $\operatorname{MTR}_{\text {asym }}(\sim 20 \%$, white arrow) between 1.2 and $2.0 \mathrm{ppm}$. Adapted from Dou et al. (121).

to be considered in clinical applications (7). Unlike the animal experiments using pseudo-continuous wave pulse radiation with multi-seconds long for maximizing saturation effect, clinical MRI scanners only allow limited saturation pulse duration as well as low duty cycle of RF amplifier, resulting in limited amount of power deposition to meet the Food and Drug Administration (FDA)-guided Specific Absorption Rate (SAR) requirements $(39,55)$. For diaCEST, this is usually not a problem, as low RF power as well as a moderate pulse duration has been widely applied (6). However, this might be a challenging issue for paraCEST, because its intrinsic fast exchange often requires high RF power which might exceed SAR limits $(6,7)$. To avoid this, the RF pulse used for CEST experiment is usually less powered or shortened, even though the saturation efficiency might be somewhat affected. In addition, rather than the direct RF saturation scheme, several other methods for CEST effect preparation can be applied alternatively, such as OPARACHEE (123) and frequency-labeled exchange transfer (FLEX) (124).

Scan time is another important aspect for clinical studies (7). To achieve limited scan time, a gradient echo (GRE) sequence is usually applied for 2D or 3D acquisition $(125,126)$, although fast spin echo sequence is also used but normally with single slice acquisition (127). Sequences with radial or spiral k-space filling strategies for rapid acquisition have also been tested for CEST imaging $(128,129)$. While good pre-clinical results were obtained, more human experiments are required to be implemented for further validation. In addition, other MR acceleration techniques 
like parallel imaging and compressed sensing, have also been combined for fast CEST imaging $(128,130)$ recently. These techniques are still very new and require further development for clinical use. Other than these, scan time can also be shortened if less images or frequency points are required for acquisition. For instance, the sequence of saturation with frequency alternating RF irradiation (SAFARI) requires short scan time for only three image acquisitions while keeping the specificity of CEST detection (131).

The interpretation of CEST signal also plays a vital role in the clinical implementation (39). Different factors, however, make data interpretation challenging. Firstly, as discussed above, CEST signals are usually contaminated by MT or NOE effect. Advanced analysis methods, such as AREX, are thus required to restore the pure CEST signal by removing background effects. Secondly, for those endogenous compounds, e.g., glycogen and Gag, the included mobile protons $(-\mathrm{OH})$ are very close to water resonance. The imperfect direct saturation due to $\mathrm{B} 0$ inhomogeneities can affect the asymmetry analysis especially at clinical $3 \mathrm{~T}$, being prone to an erroneous estimation of CEST signal. Thirdly, customized scan parameters applied can also introduce difficulties in data interpretation (39). So far, the CEST imaging protocols implemented at a variety of platforms provided by different manufactures vary substantially. The correspondingly obtained results acquired at different, e.g., saturation conditions, are thus not easy to be compared. As suggested by Zhou et al. (39), an optimized and standardized scan protocol for CEST MRI is urgently to be reached between industrial and academic communities.

\section{Conclusions}

In this work, the main and potential pre-clinical and clinical applications of CEST MRI either focusing on endogenous mobile protons from amide $(-\mathrm{NH})$, amine $(-\mathrm{NH} 2)$ and hydroxyl $(-\mathrm{OH})$ groups, or using exogenous contrast agents have been systematically reviewed. While APT imaging has been investigated in various clinical applications, other endogenous CEST effects have just been performed in pre-clinical or pilot clinical studies. Real clinical values of endogenous CEST imaging are thus still required to be further explored. For exogenous CEST MRI especially with paraCEST agents, it is still limited to translate into clinic, largely due to the potential risks of toxicity. In addition, the current status of engineered tissues in CEST MRI has been reviewed. Moreover, their potential clinical values have also been discussed and highlighted, even though the CEST studies with these materials are still at early stage.

\section{Acknowledgments}

None.

\section{Footnote}

Conflicts of Interest: W Dou, CY Lin, Y Shen, L Qian, B Wu are employee of GE Healthcare. The other authors have no conflicts of interest to declare.

\section{References}

1. Todd DJ, Kay J. Gadolinium-induced fibrosis. Annu Rev Med 2016;67:273-91.

2. Thomsen HS, Morcos SK, Almén T, Bellin MF, Bertolotto M, Bongartz G, Clement O, Leander P, Heinz-Peer G, Reimer P, Stacul F, van der Molen A, Webb JA, ESUR Contrast Medium Safety Committee. Nephrogenic systemic fibrosis and gadolinium-based contrast media: updated ESUR Contrast Medium Safety Committee guidelines. Eur Radiol 2013;23:307-18.

3. Liu SY, Han Y, Yin LP, Long L, Liu R. Toxicology Studies of a Superparamagnetic Iron Oxide Nanoparticle In Vivo. Adv Mater Res 2008;47-50:1097-100.

4. Mahmoudi M, Hofmann H, Rothen-Rutishauser B, Petri-Fink A. Assessing the in vitro and in vivo toxicity of superparamagnetic iron oxide nanoparticles. Chem Rev 2012;112:2323-38.

5. Ward KM, Aletras AH, Balaban RS. A new class of contrast agents for MRI based on proton chemical exchange dependent saturation transfer (CEST). J Magn Reson 2000;143:79-87.

6. Vinogradov E, Sherry A, Lenkinski R. CEST: from basic principles to applications, challenges and opportunities. J Magn Reson 2013;229:155-72.

7. van Zijl PC, Yadav NN. Chemical exchange saturation transfer (CEST): what is in a name and what isn't? Magn Reson Med 2011;65:927-48.

8. Wu B, Warnock G, Zaiss M, Lin C, Chen M, Zhou Z, Mu L, Nanz D, Tuura R. An overview of CEST MRI for nonMR physicists. EJNMMI Phys 2016;3:19.

9. Zhou J, Payen JF, Wilson DA, Traystman RJ, van Zijl PC. Using the amide proton signals of intracellular proteins and peptides to detect $\mathrm{pH}$ effects in MRI. Nat Med 
2003;9:1085-90.

10. Zhao X, Wen Z, Huang F, Lu S, Wang X, Hu S, Zu D, Zhou J. Saturation power dependence of amide proton transfer (APT) image contrasts in human brain tumors and strokes at 3 T. Magn Reson Med 2011;66:1033-41.

11. Zhou J, Lal B, Wilson DA, Laterra J, van Zijl PC. Amide proton transfer (APT) contrast for imaging of brain tumors. Magn Reson Med 2003;50:1120-6.

12. Wang M, Hong X, Chang CF, Li Q, Ma B, Zhang H, Xiang S, Heo HY, Zhang Y, Lee DH, Jiang S, Leigh R, Koehler RC, van Zijl PCM, Wang J, Zhou J. Simultaneous detection and separation of hyperacute intracerebral hemorrhage and cerebral ischemia using amide proton transfer MRI. Magn Reson Med 2015;74:42-50.

13. Wu Y, Zhou IY, Lu D, Manderville E, Lo EH, Zheng $\mathrm{H}$, Sun PZ. PH-sensitive amide proton transfer effect dominates the magnetization transfer asymmetry contrast during acute ischemia-quantification of multipool contribution to in vivo CEST MRI. Magn Reson Med 2018;79:1602-8.

14. Tietze A, Blicher J, Mikkelsen IK, Østergaard L, Strother MK, Smith SA, Donahue MJ. Assessment of ischemic penumbra in patients with hyperacute stroke using amide proton transfer (APT) chemical exchange saturation transfer (CEST) MRI. NMR Biomed 2014;27:163-74.

15. Zhou J, Zhu H, Lim M, Blair L, Quinones-Hinojosa A, Messina S, Eberhart C, Pomper M, Laterra J, Barker P, van Zijl P, Blakeley J. Three-Dimensional amide proton transfer MR imaging of gliomas: initial experience and comparison with gadolinium enhancement. J Magn Reson Imaging 2013;38:1119-28.

16. Togao O, Yoshiura T, Keupp J, Hiwatashi A, Yamashita K, Kikuchi K, Suzuki Y, Suzuki SO, lwaki T, Hata N, Mizoguchi M, Yoshimoto K, Sagiyama K, Takahashi M, Honda H. Amide proton transfer imaging of adult diffuse gliomas: correlation with histopathological grades. Neuro Oncol 2014;16:441-8.

17. Park JE, Kim HS, Park KJ, Choi CG, Kim SJ. Histogram analysis of amide proton transfer imaging to identify contrast-enhancing low-grade brain tumor that mimics high-grade tumor: increased accuracy of MR perfusion. Radiology 2015;277:151-61.

18. Zou T, Yu H, Jiang C, Wang X, Jiang S, Rui Q, Mei Y, Zhou J, Wen Z. Differentiating the histologic grades of gliomas preoperatively using amide proton transferweighted (APTW) and intravoxel incoherent motion MRI. NMR Biomed 2018;31. doi: 10.1002/nbm.3850.

19. Zhao X, Wen Z, Zhang G, Huang F, Lu S, Wang X,
Hu S, Chen M, Zhou J. Three-dimensional turbo-spinecho amide proton transfer MR imaging at 3-Tesla and its application to high-grade human brain tumors. Mol Imaging Biol 2013;15:114-22.

20. Zhou J, Tryggestad E, Wen Z, Lal B, ZhouT, Grossman R, Wang S, Yan K, Fu DX, Ford E, Tyler B, Blakeley J, Laterra J, van Zijl PC. Differentiation between glioma and radiation necrosis using molecular magnetic resonance imaging of endogenous proteins and peptides. Nat Med 2011;17:130-4.

21. Yu H, Lou H, Zou T, Wang X, Jiang S, Huang Z, Du Y, Jiang C, Ma L, Zhu J, He W, Rui Q, Zhou J, Wen Z. Applying protein-based amide proton transfer MR imaging to distinguish solitary brain metastases from glioblastoma. Eur Radiol 2017;27:4516-24.

22. Jiang S, Eberhart CG, Lim M, Heo HY, Zhang Y, Blair L, Wen Z, Holdhoff M, Lin D, Huang P, Qin H, QuinonesHinojosa A, Weingart JD, Barker PB, Pomper MG, Laterra J, van Zijl PCM, Blakeley JO, Zhou J. Identifying recurrent malignant glioma after treatment using amide proton transfer-weighted MR imaging: a validation study with image-guided stereotactic biopsy. Clin Cancer Res 2019;25:552-61.

23. Ma B, Blakeley JO, Hong X, Zhang H, Jiang S, Blair L, Zhang Y, Heo HY, Zhang M, van Zijl PC, Zhou J. Applying amide proton transfer-weighted MRI to distinguish pseudoprogression from true progression in malignant gliomas. J Magn Reson Imaging 2016;44:456-62.

24. Park JE, Kim HS, Park KJ, Kim SJ, Kim JH, Smith SA. Pre- and Posttreatment glioma: comparison of amide proton transfer imaging with MR spectroscopy for biomarkers of tumor proliferation. Radiology 2016;278:514-23.

25. Jiang S, Zou T, Eberhart CG, Villalobos MAV, Heo HY, Zhang Y, Wang Y, Wang X, Yu H, Du Y, van Zijl PCM, Wen Z, Zhou J. Predicting IDH mutation status in grade II gliomas using amide proton transfer-weighted (APTw) MRI. Magn Reson Med 2017;78:1100-9.

26. Jiang S, Rui Q, Wang Y, Heo HY, Zou T, Yu H, Zhang Y, Wang X, Du Y, Wen X, Chen F, Wang J, Eberhart CG, Zhou J, Wen Z. Discriminating MGMT promoter methylation status in patients with glioblastoma employing amide proton transfer-weighted MRI metrics. Eur Radiol 2018;28:2115-23.

27. Paech D, Windschuh J, Oberhollenzer J, Dreher C, Sahm F, Meissner JE, Goerke S, Schuenke P, Zaiss M, Regnery S, Bickelhaupt S, Bäumer P, Bendszus M, Wick 
W, Unterberg A, Bachert P, Ladd ME, Schlemmer HP, Radbruch A. Assessing the predictability of IDH mutation and MGMT methylation status in glioma patients using relaxation-compensated multipool CEST MRI at 7.0 T. Neuro Oncol 2018;20:1661-71.

28. Dula AN, Arlinghaus LR, Dortch RD, Dewey BE, Whisenant JG, Ayers GD, Yankeelov TE, Smith SA. Amide proton transfer imaging of the breast at 3T: establishing reproducibility and possible feasibility assessing chemotherapy response. Magn Reson Med 2013;70:216-24.

29. Dula AN, Dewey BE, Arlinghaus LR, Williams JM, Klomp D, Yankeelov TE, Smith S. Optimization of 7-T chemical exchange saturation transfer parameters for validation of glycosaminoglycan and amide proton transfer of fibroglandular breast tissue. Radiology 2015;275:255-61.

30. Krikken E, Khlebnikov V, Zaiss M, Jibodh RA, van Diest PJ, Luijten PR, Klomp DWJ, van Laarhoven HWM, Wijnen JP. Amide chemical exchange saturation transfer at $7 \mathrm{~T}$ : a possible biomarker for detecting early response to neoadjuvant chemotherapy in breast cancer patients. Breast Cancer Res 2018;20:51.

31. Klomp DW, Dula AN, Arlinghaus LR, Italiaander M, Dortch RD, Zu Z, Williams JM, Gochberg DF, Luijten PR, Gore JC, Yankeelov TE, Smith SA. Amide proton transfer imaging of the human breast at 7T: development and reproducibility. NMR Biomed 2013;26:1271-7.

32. Jia G, Abaza R, Williams JD, Zynger DL, Zhou J, Shah ZK, Patel M, Sammet S, Wei L, Bahnson RR, Knopp MV. Amide proton transfer MR imaging of prostate cancer: a preliminary study. J Magn Reson Imaging 2011;33:647-54.

33. Takayama Y, Nishie A, Sugimoto M, Togao O, Asayama Y, Ishigami K, Ushijima Y, Okamoto D, Fujita N, Yokomizo A, Keupp J, Honda H. Amide proton transfer (APT) magnetic resonance imaging of prostate cancer: comparison with Gleason scores. MAGMA 2016;29:671-9.

34. Wang R, Li SY, Chen M, Zhou JY, Peng DT, Zhang C, Dai YM. Amide proton transfer magnetic resonance imaging of Alzheimer's disease at 3.0 Tesla: a preliminary study. Chin Med J (Engl) 2015;128:615-9.

35. Li C, Peng S, Wang R, Chen H, Su W, Zhao X, Zhou J, Chen M. Chemical exchange saturation transfer MR imaging of Parkinson's disease at 3 Tesla. Eur Radiol 2014;24:2631-9.

36. Li C, Wang R, Chen H, Su W, Li S, Zhao X, Zhou J, Qiao J, Lou B, Song G, Chen M. Chemical exchange saturation transfer MR imaging is superior to diffusion- tensor imaging in the diagnosis and severity evaluation of Parkinson's disease: a study on substantia nigra and striatum. Front Aging Neurosci 2015;7:198.

37. Li C, Chen M, Zhao X, Wang R, Chen H, Su W, Li S, Lou B, Song G, Zhang S, Zhang J, Zhou J. Chemical exchange saturation transfer MRI signal loss of the substantia nigra as an imaging biomarker to evaluate the diagnosis and severity of Parkinson's disease. Front Neurosci 2017;11:489.

38. By S, Barry RL, Smith AK, Lyttle BD, Box BA, Bagnato FR, Pawate S, Smith SA. Amide proton transfer CEST of the cervical spinal cord in multiple sclerosis patients at $3 \mathrm{~T}$. Magn Reson Med 2018;79:806-14.

39. Zhou J, Heo HY, Knutsson L, van Zijl PCM, Jiang S. APT-weighted MRI: Techniques, current neuro applications, and challenging issues. J Magn Reson Imaging 2019;50:347-64.

40. Zhou J, Hong X, Zhao X, Gao JH, Yuan J. APT-weighted and NOE-weighted image contrasts in glioma with different RF saturation powers based on magnetization transfer ratio asymmetry analyses. Magn Reson Med 2013;70:320-7.

41. Heo HY, Zhang Y, Lee DH, Hong X, Zhou J. Quantitative assessment of amide proton transfer (APT) and nuclear overhauser enhancement (NOE) imaging with extrapolated semi-solid magnetization transfer reference (EMR) signals: Application to a rat glioma model at 4.7 Tesla. Magn Reson Med 2016;75:137-49.

42. Heo HY, Zhang Y, Jiang S, Lee DH, Zhou J. Quantitative assessment of amide proton transfer (APT) and nuclear overhauser enhancement (NOE) imaging with extrapolated semisolid magnetization transfer reference (EMR) signals: II. Comparison of three EMR models and application to human brain glioma at 3 Tesla. Magn Reson Med 2016;75:1630-9.

43. Heo HY, Zhang Y, Burton TM, Jiang S, Zhao Y, van Zijl PCM, Leigh R, Zhou J. Improving the detection sensitivity of $\mathrm{pH}$-weighted amide proton transfer MRI in acute stroke patients using extrapolated semisolid magnetization transfer reference signals. Magn Reson Med 2017;78:871-80.

44. Zaiss M, Windschuh J, Paech D, Meissner JE, Burth S, Schmitt B, Kickingereder P, Wiestler B, Wick W, Bendszus M, Schlemmer HP, Ladd ME, Bachert P, Radbruch A. Relaxation-compensated CEST-MRI of the human brain at 7T: Unbiased insight into NOE and amide signal changes in human glioblastoma. Neuroimage 2015;112:180-8. 
45. Jones CK, Huang A, Xu J, Edden RA, Schär M, Hua J, Oskolkov N, Zacà D, Zhou J, McMahon MT, Pillai JJ, van Zijl PC. Nuclear Overhauser enhancement (NOE) imaging in the human brain at 7T. Neuroimage 2013;77:114-24.

46. Zaiss M, Xu J, Goerke S, Khan IS, Singer RJ, Gore JC, Gochberg DF, Bachert P. Inverse Z-spectrum analysis for spillover-, MT-, and T1-corrected steady-state pulsed CEST-MRI-application to $\mathrm{pH}$-weighted MRI of acute stroke. NMR Biomed 2014;27:240-52.

47. Zaiss M, Windschuh J, Goerke S, Paech D, Meissner JE, Burth S, Kickingereder P, Wick W, Bendszus M, Schlemmer HP, Ladd ME, Bachert P, Radbruch A. Downfield-NOE-suppressed amide-CEST-MRI at 7 Tesla provides a unique contrast in human glioblastoma. Magn Reson Med 2017;77:196-208.

48. Sun PZ, Farrar CT, Sorensen AG. Correction for artifacts induced by $\mathrm{B}(0)$ and $\mathrm{B}(1)$ field inhomogeneities in $\mathrm{pH}$ sensitive chemical exchange saturation transfer (CEST) imaging. Magn Reson Med 2007;58:1207-15.

49. Kim M, Gillen J, Landman BA, Zhou J, van Zijl PC. Water saturation shift referencing (WASSR) for chemical exchange saturation transfer (CEST) experiments. Magn Reson Med 2009;61:1441-50.

50. Schuenke P, Windschuh J, Roeloffs V, Ladd ME, Bachert P, Zaiss M. Simultaneous mapping of water shift and B1 (WASABI)-Application to field-Inhomogeneity correction of CEST MRI data. Magn Reson Med 2017;77:571-580.

51. Mehrabian H, Myrehaug S, Soliman H, Sahgal A, Stanisz GJ. Evaluation of glioblastoma response to therapy with chemical exchange saturation transfer. Int J Radiat Oncol Biol Phys 2018;101:713-23.

52. Regnery S, Adeberg S, Dreher C, Oberhollenzer J, Meissner JE, Goerke S, Windschuh J, Deike-Hofmann K, Bickelhaupt S, Zaiss M, Radbruch A, Bendszus M, Wick W, Unterberg A, Rieken S, Debus J, Bachert P, Ladd ME, Schlemmer HP, Paech D. Chemical exchange saturation transfer MRI serves as predictor of early progression in glioblastoma patients. Oncotarget 2018;9:28772-83.

53. Meissner JE, Korzowski A, Regnery S, Goerke S, Breitling J, Floca RO, Debus J, Schlemmer HP, Ladd ME, Bachert P, Adeberg S, Paech D. Early response assessment of glioma patients to definitive chemoradiotherapy using chemical exchange saturation transfer imaging at $7 \mathrm{~T}$. J Magn Reson Imaging 2019;50:1268-77.

54. Paech D, Dreher C, Regnery S, Meissner JE, Goerke S, Windschuh J, Oberhollenzer J, Schultheiss M, DeikeHofmann K, Bickelhaupt S, Radbruch A, Zaiss M,
Unterberg A, Wick W, Bendszus M, Bachert P, Ladd ME, Schlemmer HP. Relaxation-compensated amide proton transfer (APT) MRI signal intensity is associated with survival and progression in high-grade glioma patients. Eur Radiol 2019;29:4957-67.

55. Jones KM, Pollard AC, Pagel MD. Clinical applications of chemical exchange saturation transfer (CEST) MRI. J Magn Reson Imaging 2018;47:11-27.

56. Cai K, Haris M, Singh A, Kogan F, Greenberg JH, Hariharan H, Detre JA, Reddy R. Magnetic resonance imaging of glutamate. Nat Med 2012;18:302-6.

57. Nanga RPR, Debrosse C, Kumar D, Roalf D, McGeehan B, D'Aquilla K, Borthakur A, Hariharan H, Reddy D, Elliott M, Detre JA, Epperson CN, Reddy R. Reproducibility of 2D GluCEST in healthy human volunteers at 7T. Magn Reson Med 2018;80:2033-9.

58. Kogan F, Haris M, Singh A, Cai K, Debrosse C, Nanga RP, Hariharan H, Reddy R. Methods for high-resolution imaging of creatine in vivo using chemical exchange saturation transfer. Magn Reson Med 2014;71:164-72.

59. Dou W, Palomero-Gallagher N, van Tol MJ, Kaufmann J, Zhong K, Bernstein HG, Heinze HJ, Speck O, Water M. Systematic regional variations of GABA, glutamine, and glutamate concentrations follow receptor fingerprints of human cingulate cortex. J Neurosci 2013;33:12698-704.

60. Haris M, Nath K, Cai K, Singh A, Crescenzi R, Kogan F, Verma G, Reddy S, Hariharan H, Melhem ER, Reddy R. Imaging of glutamate neurotransmitter alterations in Alzheimers's disease. NMR Biomed 2013;26:386-91.

61. O'Grady KP, Dula AN, Lyttle BD, Thompson LM, Conrad BN, Box BA, McKeithan LJ, Pawate S, Bagnato F, Landman BA, Newhouse P, Smith SA. Glutamatesensitive imaging and evaluation of cognitive impairment in multiple sclerosis. Mult Scler 2019;25:1580-92.

62. Roalf DR, Nanga RPR, Rupert PE, Hariharan H, Quarmley M, Calkins ME, Dress E, Prabhakaran K, Elliott MA, Moberg PJ, Gur RC, Gur RE, Reddy R, Turetsky BI. Glutamate imaging (GluCEST) reveals lower brain GluCEST contrast in patients on the pyschosis spectrum. Mol Psychiatry 2017;22:1298-305.

63. Davis KA, Nanga RP, Das S, Chen SH, Hadar PN, Pollard JR, Lucas TH, Shinohara RT, Litt B, Hariharan H, Elliott MA, Detre JA, Reddy R. Glutamate imaging (GluCEST) lateralizes epileptic foci in nonlesional temporal lobe epilepsy. Sci Transl Med 2015;7:309ra161.

64. Neal A, Moffat BA, Stein JM, Nanga RPR, Desmond P, Shinohara RT, Hariharan H, Glarin R, Drummond K, Morokoff A, Kwan P, Reddy R, O’Brien TJ, Davis KA. 
Glutamate weighted imaging contrast in gliomas with

7 Tesla magnetic resonance imaging. Neuroimage Clin 2019;22:101694.

65. Kogan F, Singh A, Debrosse C, Haris M, Cai K, Nanga RP, Elliott M, Hariharan H, Reddy R. Imaging of glutamate in the spinal cord using GluCEST. Neuroimage 2013;77:262-7.

66. Chance B, Williams GR. Respiratory enzymes in oxidative phosphorylation. III. The steady state. J Biol Chem 1955;217:409-27.

67. Kogan F, Haris M, Debrosse C, Singh A, Nanga RP, Cai $\mathrm{K}$, Hariharan H, Reddy R. In vivo chemical exchange saturation transfer imaging of creatine (CrCEST) in skeletal muscle at 3T. J Magn Reson Imaging 2014;40:596-602.

68. Rerich E, Zaiss M, Korzowski A, Ladd ME, Bachert P. Relaxation-compensated CEST-MRI at $7 \mathrm{~T}$ for mapping of creatine content and $\mathrm{pH}$-preliminary application in human muscle tissue in vivo. NMR Biomed 2015;28:1402-12.

69. Zhou Z, Nguyen C, Chen Y, Shaw JL, Deng Z, Xie Y, Dawkins J, Marbán E, Li D. Optimized CEST cardiovascular magnetic resonance for assessment of metabolic activity in the heart. J Cardiovasc Magn Reson 2017;19:95.

70. Singh A, Haris M, Cai K, Kassey VB, Kogan F, Reddy D, Hariharan H, Reddy R. Chemical exchange saturation transfer resonance imaging of human knee cartilage at $3 \mathrm{~T}$ and 7 T. Magn Reson Med 2012;68:588-94.

71. Schreiner MM, Zbýn Š, Schmitt B, Weber M, Domayer S, Windhager R, Trattnig S, Mlynárik V. Reproducibility and regional variations of an improved gagCEST protocol for the in vivo evaluation of knee cartilage at 7T. MAGMA 2016;29:513-21.

72. Krishnamoorthy G, Nanga RPR, Bagga P, Hariharan $\mathrm{H}$, Reddy R. High quality three-dimensional gagCEST imaging of in vivo human knee cartilage at 7 Tesla. Magn Reson Med 2017;77:1866-73.

73. van Zijl PC, Jones CK, Ren J, Malloy CR, Sherry AD. MRI detection of glycogen in vivo by using chemical exchange saturation transfer imaging (glycoCEST). Proc Natl Acad Sci U S A 2007;104:4359-64.

74. Lee YH, Yang J, Jeong HK, Suh JS. Assessment of the patellofemoral cartilage: correlation of knee pain score with magnetic resonance cartilage grading and magnetization transfer ratio asymmetry of glycosaminoglycan chemical exchange saturation transfer. Magn Reson Imaging 2017;35:61-8.
75. Schmitt B, Zbýn S, Stelzeneder D, Jellus V, Paul D, Lauer L, Bachert P, Trattnig S. Cartilage quality assessment by using glycosaminoglycan chemical exchange saturation transfer and (23) Na MR imaging at 7 T. Radiology 2011;260:257-64.

76. Rehnitz C, Kupfer J, Streich NA, Burkholder I, Schmitt B, Lauer L, Kauczor HU, Weber MA. Comparison of biochemical cartilage imaging techniques at 3 T MRI. Osteoarthritis Cartilage 2014;22:1732-42.

77. Kim M, Chan Q, Anthony MP, Cheung KM, Samartzis D, Khong PL. Assessment of glycosaminoglycan distribution in human lumbar intervertebral discs using chemical exchange saturation transfer at $3 \mathrm{~T}$ : feasibility and initial experience. NMR Biomed 2011;24:1137-44.

78. Schleich C, Müller-Lutz A, Zimmermann L, Boos J, Schmitt B, Wittsack HJ, Antoch G, Miese F. Biochemical imaging of cervical intervertebral discs with glycosaminoglycan chemical exchange saturation transfer magnetic resonance imaging: feasibility and initial results. Skeletal Radiol 2016;45:79-85.

79. Schleich C, Müller-Lutz A, Matuschke F, Sewerin P, Sengewein R, Schmitt B, Ostendorf B, Wittsack HJ, Stanke K, Antoch G, Miese F. Glycosaminoglycan chemical exchange saturation transfer of lumbar intervertebral discs in patients with spondyloarthritis. J Magn Reson Imaging 2015;42:1057-63.

80. Schleich C, Müller-Lutz A, Eichner M, Schmitt B, Matuschke F, Bittersohl B, Zilkens C, Wittsack HJ, Antoch G, Miese F. Glycosaminoglycan chemical exchange saturation transfer of lumbar intervertebral discs in healthy volunteers. Spine 2016;41:146-52.

81. Wada T, Togao O, Tokunaga C, Funatsu R, Yamashita Y, Kobayashi K, Nakamura Y, Honda H. Glycosaminoglycan chemical exchange saturation transfer in human lumbar intervertebral discs: effect of saturation pulse and relationship with low back pain. J Magn Reson Imaging 2017;45:863-71.

82. Müller-Lutz A, Schleich C, Schmitt B, Antoch G, Matuschke F, Quentin M, Wittsack HJ, Miese F. Gender, $\mathrm{BMI}$ and $\mathrm{T} 2$ dependencies of glycosaminoglycan chemical exchange saturation transfer in intervertebral discs. Magn Reson Imaging 2016;34:271-5.

83. Kogan F, Hariharan H, Reddy R. Chemical exchange saturation transfer (CEST) imaging: description of technique and potential clinical applications. Curr Radiol Rep 2013;1:102-14.

84. Walker-Samuel S, Ramasawmy R, Torrealdea F, Rega M, Rajkumar V, Johnson SP, Richardson S, Gonçalves M, 
Parkes HG, Arstad E, Thomas DL, Pedley RB, Lythgoe MF, Golay X. In vivo imaging of glucose uptake and metabolism in tumors. Nat Med 2013;19:1067-72.

85. Nasrallah FA, Page`s G, Kuchel PW, Golay X, Chuang $\mathrm{KH}$. Imaging brain deoxyglucose uptake and metabolism by glucoCEST MRI. J Cereb Blood Flow Metab 2013;33:1270-8.

86. Chan KW, McMahon MT, Kato Y, Liu G, Bulte JW, Bhujwalla ZM, Artemov D, van Zijl PC. Natural D-glucose as a biodegradable MRI contrast agent for detecting cancer. Magn Reson Med 2012;68:1764-73.

87. Wang J, Weygand J, Hwang KP, Mohamed AS, Ding Y, Fuller CD, Lai SY, Frank SJ, Zhou J. Magnetic resonance imaging of glucose uptake and metabolism in patients with head and neck cancer. Sci Rep 2016;6:30618.

88. Xu X, Yadav NN, Knutsson L, Hua J, Kalyani R, Hall E, Laterra J, Blakeley J, Strowd R, Pomper M, Barker P, Chan K, Liu G, McMahon MT, Stevens RD, van Zijl PC. Dynamic glucose-enhanced (DGE) MRI: translation to human scanning and first results in glioma patients. Tomography 2015;1:105-14.

89. Jin T, Iordanova B, Hitchens TK, Modo M, Wang P, Mehrens H, Kim SG. Chemical exchange-sensitive spinlock (CESL) MRI of glucose and analogs in brain tumors. Magn Reson Med 2018;80:488-495.

90. Schuenke P, Paech D, Koehler C, Windschuh J, Bachert P, Ladd ME, Schlemmer HP, Radbruch A, Zaiss M. Fast and quantitative T1 $\rho$-weighted dynamic glucose enhanced MRI. Sci Rep 2017;7:42093.

91. Paech D, Schuenke P, Koehler C, Windschuh J, Mundiyanapurath S, Bickelhaupt S, Bonekamp D, Bäumer P, Bachert P, Ladd ME, Bendszus M, Wick W, Unterberg A, Schlemmer HP, Zaiss M, Radbruch A. T1 $\rho$-weighted dynamic glucose-enhanced MR imaging in the human brain. Radiology 2017;285:914-22.

92. Longo DL, Dastrù W, Digilio G, Keupp J, Langereis S, Lanzardo S, Prestigio S, Steinback O, Terreno E, Uggeri F, Aime S. Iopamidol as a responsive MRI-chemical exchange saturation transfer contrast agent for $\mathrm{pH}$ mapping of kidneys: in vivo studies in mice at 7T. Magn Reson Med 2011;65:202-11.

93. Moon BF, Jones KM, Chen LQ, Liu P, Randtke EA, Howison CM, Pagel MD. A comparison of iopromide and iopamidol, two acidoCEST MRI contrast media that measure tumor extracellular $\mathrm{pH}$. Contrast Media Mol Imaging 2015;10:446-55.

94. Chen LQ, Randtke EA, Jones KM, Moon BF, Howison CM, Pagel MD. Evaluations of tumor acidosis within in vivo tumor models using parametric maps generated with acido CEST MRI. Mol Imaging Biol 2015;17:488-96.

95. Chen LQ, Howison CM, Jeffery JJ, Robey IF, Kuo PH, Pagel MD. Evaluations of extracellular $\mathrm{pH}$ within in vivo tumors using acidoCEST MRI. Magn Reson Med 2014;72:1408-17.

96. Müller-Lutz A, Khalil N, Schmitt B, Jellus V, Pentang G, Oeltzschner G, Antoch G, Lanzman RS, Wittsack HJ. Pilot study of lopamidol-based quantitative $\mathrm{pH}$ imaging on a clinical 3T MR scanner. MAGMA 2014;27:477-85.

97. Liu G, Moake M, Har-el YE, Long CM, Chan KW, Cardona A, Jamil M, Walczak P, Gilad AA, Sgouros G, van Zijl PC, Bulte JW, McMahon MT. In vivo multicolor molecular MR imaging using diamagnetic chemical exchange saturation transfer liposomes. Magn Reson Med 2012;67:1106-13.

98. Chan KW, Yu T, Qiao Y, Liu Q, Yang M, Patel H, Liu G, Kinzler KW, Vogelstein B, Bulte JW, van Zijl PC, Hanes J, Zhou S, McMahon MT. A diaCEST MRI approach for monitoring liposomal accumulation in tumors. J Control Release 2014;180:51-9.

99. Aime S, Barge A, Delli Castelli D, Fedeli F, Mortillaro A, Nielsen FU, Terreno E. Paramagnetic lanthanide(III) complexes as $\mathrm{pH}$-sensitive chemical exchange saturation transfer (CEST) contrast agents for MRI applications. Magn Reson Med 2002;47:639-48.

100.Aime S, Delli Castelli D, Fedeli F, Terreno E. A paramagnetic MRI-CEST agent responsive to lactate concentration. J Am Chem Soc. 2002;124(32):9364-5.

101.Zhang S, Winter P, Wu K, Sherry AD. A novel europium(III)-based MRI contrast agent. J Am Chem Soc 2001;123:1517-8.

102. Olatunde AO, Dorazio SJ, Spernyak JA, Morrow JR. The NiCEST approach: nickel(II) paraCEST MRI contrast agents. J Am Chem Soc 2012;134:18503-5.

103. Sheth VR, Liu G, Li Y, Pagel MD. Improved pH measurements with a single PARACEST MRI contrast agent. Contrast Media Mol Imaging 2012;7:26-34.

104. Delli Castelli D, Dastrù W, Terreno E, Cittadino E, Mainini F, Torres E, Spadaro M, Aime S. In vivo MRI multicontrast kinetic analysis of the uptake and intracellular trafficking of paramagnetically labeled liposomes. J Control Release 2010;144:271-9.

105.Li AX, Suchy M, Li C, Gati JS, Meakin S, Hudson RH, Menon RS, Bartha R. In vivo detection of MRIPARACEST agents in mouse brain tumors at 9.4T. Magn Reson Med 2011;66:67-72.

106. Vinogradov E, He H, Lubag A, Balschi JA, Sherry AD, 
Lenkinski RE. MRI detection of paramagnetic chemical exchange effects in mice kidneys in vivo. Magn Reson Med 2007;58:650-5.

107.Ren J, Trokowski R, Zhang S, Malloy CR, Sherry AD. Imaging the tissue distribution of glucose in livers using a PARACEST sensor. Magn Reson Med 2008;60:1047-55.

108. Griffith LG and Naughton G. Tissue engineeringcurrent challenges and expanding opportunities. Science 2002;295:1009-14.

109.Xu H, Othman SF, Magin RL. Monitoring tissue engineering using magnetic resonance imaging. J Biosci Bioeng 2008;106:515-27.

110. Ossipov DA, Piskounova S, Varghese O, Hilborn J. Functionalization of hyaluronic acid with chemoselective groups via a disulfide-based protection strategy for in situ formation of mechanically stable hydrogels. Biomacromolecules 2010;11:2247-54.

111. Varghese OP, Sun W, Hilborn J, Ossipov D. In situ cross-linkable high molecular weight hyaluronanbisphosphonate conjugate for localized delivery and cellspecific targeting: a hydrogel linked prodrug approach. J Am Chem Soc 2009;131:8781-83.

112. Martínez-Sanz E, Ossipov D, Hilborn J, Larsson S, Jonsson K, Varghese O. Bone reservoir: Injectable hyaluronic acid hydrogel for minimal invasive bone augmentation. J Control Release 2011;152:232-40.

113. Goffeney N, Bulte J, Duyn J, Bryant LH Jr, van Zijl PC. Sensitive NMR detection of cationic-polymer-based gene delivery systems using saturation transfer via proton exchange. J Am Chem Soc 2001;123:8628-9.

114.Elzes MR, Akeroyd N, Engbersen J, Paulusse J. Disulfidefunctional poly(amido amine)s with tunable degradability for gene delivery. J Control Release 2016;244:357-65.

115.Ekkelenkamp AE, Jansman MM, Roelofs K, Engbersen JF, Paulusse JM. Surfactant-free preparation of highly stable zwitterionic poly(amido amine) nanogels with minimal cytotoxicity. Acta Biomater 2016;30:126-34.

116. Dorsey S, Haris M, Singh A, Witschey W, Rodell C, Kogan F, Reddy R, Burdick J. Visualization of injectable hydrogels using chemical exchange saturation transfer MRI. ACS Biomater Sci Eng 2015;1:227-37.

117.Liang Y, Bar-shir A, Song X, Gilad A, Walczak P, Bulte J. Label-free imaging of gelatin-containing hydrogel scaffolds. Biomaterials 2015;42:144-50.

118.Jin T, Nicholls F, Crum W, Ghuman H, Badylak S, Modo M. Diamagnetic chemical exchange saturation transfer (diaCEST) affords magnetic resonance imaging of extracellular matrix hydrogel implantation in a rat model of stroke. Biomaterials 2017;113:176-90.

119.Sun Y, Ventura M, Oosterwijk E, Jansen JA, Walboomers XF, Heerschap A. Zero Echo Time Magnetic Resonance Imaging of Contrast-Agent-Enhanced Calcium Phosphate Bone Defect Fillers. Tissue Eng Part C Methods 2013;19:281-7.

120.Dou W, Song X, Bermejo D, Ossipov D, Bulte JWM, Heerschap A. Chemical exchange saturation transfer magnetic resonance imaging of injectable functionalized hyaluronic acid hydrogel. In: Proceedings of the 34th Annual Scientific Meeting ESMRMB, Barcelona, Spain, 2017;S76.

121. Dou W, Paulusse J, Janke HP, Song X, Xu J, Bulte JWM, Heerschap A. Chemical exchange saturation transfer magnetic resonance imaging of functionalized poly $(\mathrm{N}$, N'-methylene bisacrylamide 4-aminobutanol) gel. In: Proceedings of the 26th Joint Annual Scientific Meeting ISMRM-ESMRMB. Paris, France, 2018;p5124.

122. Kouwer PH, Koepf M, Le Sage VA, Jaspers M, van Buul AM, Eksteen-Akeroyd ZH, Woltinge T, Schwartz E, Kitto HJ, Hoogenboom R, Picken SJ, Nolte RJ, Mendes $\mathrm{E}$, Rowan AE. Responsive biomimetic networks from polyisocyanopeptide hydrogels. Nature 2013;493:651-5.

123. Vinogradov E, Zhang S, Lubag A, Balschi JA, Sherry AD, Lenkinski RE. On resonance low B1 pulses for imaging of the effects of PARACEST agents. J Magn Reson 2005;176:54-63.

124. Friedman JI, McMahon MT, Stivers JT, van Zijl PC. Indirect detection of labile solute proton spectra via the water signal using frequency-labeled exchange (FLEX) transfer. J Am Chem Soc 2010;132:1813-15.

125.Dai Z, Ji J, Xiao G, Yan G, Li S, Zhang G, Lin Y, Shen $\mathrm{Z}, \mathrm{Wu}$ R. Magnetization transfer prepared gradient echo MRI for CEST imaging. PLoS One 2014;9:e112219.

126.Schmitt B, Zamecnik P, Zaiss M, Rerich E, Schuster L, Bachert P, Schlemmer HP. A new contrast in MR mammography by means of chemical exchange saturation transfer (CEST) imaging at 3 Tesla: preliminary results. Rofo 2011;183:1030-6.

127.Deng M, Chen SZ, Yuan J, Chan Q, Zhou J, Wang YX. Chemical exchange saturation transfer (CEST) MR technique for liver imaging at 3.0 Tesla: an evaluation of different offset number and an after-meal and over-nightfast comparison. Mol Imaging Biol 2016;18:274-82.

128. Kim J, Johnson CP, Wang D, Sun PZ. Accelerated CEST MRI using parallel imaging acquisition of goldenangle radial ordering scheme and compressed sensing reconstruction. In: Proceedings of the 23rd Annual 
Scientific Meeting ISMRM. Toronto, Canada, 2015;p3621. 129. Wu B, Li R, Lin CH, Lin M, Zhou Z. Rapid 3D spiral CEST. In: Proceedings of the 24th Annual Scientific Meeting ISMRM. Singapore, 2016;p1517.

130. Heo HY, Zhang Y, Lee DH, Jiang S, Zhao X, Zhou J. Accelerating chemical exchange saturation transfer (CEST) MRI by combining compressed sensing and sensitivity

Cite this article as: Dou W, Lin CY, Ding H, Shen Y, Dou C, Qian L, Wen B, Wu B. Chemical exchange saturation transfer magnetic resonance imaging and its main and potential applications in pre-clinical and clinical studies. Quant Imaging Med Surg 2019;9(10):1747-1766. doi: 10.21037/ qims.2019.10.03 encoding techniques. Magn Reson Med 2017;77:779-86. 131. Scheidegger R, Vinogradov E, Alsop DC. Amide proton transfer imaging with improved robustness to magnetic field inhomogeneity and magnetization transfer asymmetry using saturation with frequency alternating RF irradiation. Magn Reson Med 2011;66:1275-85. 